2012

\title{
Can Oysters Crassostrea virginica Develop Resistance to Dermo Disease in the Field: The Impediment Posed by Climate Cycles
}

Eric N. Powell

John M. Klinck

Old Dominion University, jklinck@odu.edu

Ximing Guo

Eileen E. Hofmann

Old Dominion University, ehofmann@odu.edu

Susan E. Ford

See next page for additional authors

Follow this and additional works at: https://digitalcommons.odu.edu/ccpo_pubs

Part of the Marine Biology Commons, and the Oceanography Commons

\section{Repository Citation}

Powell, Eric N.; Klinck, John M.; Guo, Ximing; Hofmann, Eileen E.; Ford, Susan E.; and Bushek, David, "Can Oysters Crassostrea virginica Develop Resistance to Dermo Disease in the Field: The Impediment Posed by Climate Cycles" (2012). CCPO Publications. 74.

https://digitalcommons.odu.edu/ccpo_pubs/74

\section{Original Publication Citation}

Powell, E.N., Klinck, J.M., Guo, X., Hofmann, E.E., Ford, S.E., \& Bushek, D. (2012). Can oysters Crassostrea virginica develop resistance to dermo disease in the field: The impediment posed by climate cycles. Journal of Marine Research, 70(2-3), 309-355. 
Authors

Eric N. Powell, John M. Klinck, Ximing Guo, Eileen E. Hofmann, Susan E. Ford, and David Bushek 


\title{
Can oysters Crassostrea virginica develop resistance to dermo disease in the field: The impediment posed by climate cycles
}

\author{
by Eric N. Powell ${ }^{1,2}$, John M. Klinck ${ }^{3}$, Ximing Guo ${ }^{1}$, Eileen E. Hofmann ${ }^{3}$, \\ Susan E. Ford ${ }^{1}$ and David Bushek ${ }^{1}$
}

\begin{abstract}
Populations of eastern oysters, Crassostrea virginica, are commonly limited by mortality from dermo disease. Little development of resistance to Perkinsus marinus, the dermo pathogen, has occurred, despite the high mortality rates and frequency of epizootics. Can the tendency of the parasite to exhibit cyclic epizootics limit the oyster's response to the disease despite the presence of alleles apparently conferring disease resistance? We utilize a gene-based population dynamics model to simulate the development of disease resistance in Crassostrea virginica populations exposed to cyclic mortality encompassing periodicities expected of dermo disease over the geographic range at which epizootics have been observed. Cyclic disease reduces the incremental rate of development of disease resistance profoundly, primarily as a consequence of a reduction in the time-integrated population mortality rate, which will be about half the cycle's apogean rate. Cyclicity enhances host survival for more susceptible genotypes at cycle nadir. Moreover, alleles conferring disease resistance typically are rare in the naïve population. Cyclicity permits these rare alleles to drift and most often, that drift is towards lower frequencies because fewer animals carrying these alleles predestines a lower probability of their successful dissemination during sweepstakes reproduction at cycle nadir. Variations in population dynamics, such as differences in abundance, fecundity at size, and in the number of individuals successfully producing recruits varied the outcome little. The large number of loci contributing to disease resistance, the cyclic nature of the exposure relieving the population in predictable time units from selection pressure, and the tendency for conditions that might enhance development of disease resistance such as rapid growth to be counterbalanced by multiple yearly spawnings, hamper the rapid development of disease resistance. Unfortunately, epizootic mortality rates at cycle apogee, twice that observed at cycle nadir or prior to onset of disease, are consequential from the standpoint of population sustainability, but much less consequential for driving selection towards disease resistance. The periodicity of dermo epizootics may doom oyster populations to an extended period of low abundance, during which disease resistance slowly improves; bit by bit limiting the depredations of the disease.
\end{abstract}

1. Rutgers University, Institute of Marine and Coastal Sciences and The New Jersey Agricultural Experiment Station, Haskin Shellfish Research Laboratory, Port Norris, New Jersey, 08349, U.S.A.

2. Corresponding author. email: eric@hsrl.rutgers.edu

3. Center for Coastal Physical Oceanography, Department of Ocean, Earth and Atmospheric Sciences, Old Dominion University, Norfolk, Virginia, 23508, U.S.A. 


\section{Introduction}

In the modern age, the abundance of eastern oysters, Crassostrea virginica, is commonly limited by mortality produced by disease (Andrews, 1988; Fegley et al., 2003; Powell et al., 2009c). Resistance to MSX disease (causative agent Haplosporidium nelsoni) has developed in a number of populations (Ford and Haskin, 1982; Ford, 1988; Burreson, 1991; Ford and Tripp, 1996; Carnegie and Burreson, 2011), but the development of resistance to dermo disease (causative agent Perkinsus marinus) would appear much more muted (Ford et al., 1999; Encomio et al., 2005; Brown et al., 2005a,b), despite the high mortality rates and frequency of epizootics (e.g., Soniat and Gauthier, 1989; Crosby and Roberts, 1990; Powell et al., 1996; Burreson and Ragone Calvo, 1996; Volety et al., 2000; Ragone Calvo et al., 2001). Powell et al. (2011a) considered whether aspects of the host's genetics in concert with its population dynamics might limit the population's development of disease resistance despite the apparent opportunity afforded by individuals with alleles conferring disease resistance or tolerance ${ }^{4}$. They found that resistance to dermo disease in simulated populations increased over time with increases more or less in proportion to the increment in mortality rate imposed by the disease. However, the simulations revealed that a significant population response occurs even at its most precipitate rate on decadal to vicennial time scales. As the mortality rate declines with increasing disease resistance, the rate of improvement in disease resistance commensurately diminishes. Thus, disease resistance develops over decadal time scales at a $30 \%$ per year increment in mortality rate ${ }^{5}$ to $40 \%$ from the pre-disease level of $10 \%$, but when mortality rate declines to $25 \%$ per year, a $15 \%$ increment, the rate of development of disease resistance falls to half-century time scales. Notwithstanding what at first glance seems to be an abysmally slow response, the rate of development of resistance predicted by Powell et al. (2011a) is sufficiently fast that oysters with increased resistance to dermo disease should have been observed in regions where dermo has been monitored for long periods of time. This includes the Gulf of Mexico, Chesapeake Bay, and Delaware Bay (Wilson et al., 1990; Andrews, 1996; Ford, 1996; Ray, 1996; Cook et al., 1998; Ragone Calvo et al., 2001). Powell et al. (2011a) provide tantalizing data suggestive of a modicum of response over two decades in Delaware Bay, but the time series is still too short for verification and the degree of response is still limited in comparison to what might be anticipated from the increased mortality accompanying the disease (Powell et al., 2008).

One of the salient characteristics of dermo disease is the tendency for epizootics to follow climate cycles. In the Gulf of Mexico, the El Niño-Southern Oscillation generates an approximately four-year cycle in precipitation with a resultant salinity cycle of the

4. Hereafter, we apply the term 'disease resistance' to both disease resistance and tolerance (e.g., Schneider and Ayres, 2008), recognizing them to be indistinguishable in their effect on population dynamics, as inferred from presently available time-series data.

5. Throughout, the term 'mortality rate' applies to the fraction dying per year. Values given are not true rates; rather, they are equivalent to $1-e^{-m t}$ in the equation $N_{t}=N_{\circ} e^{-m t}$ with $m$ in units of $\mathrm{yr}^{-1}$ and $t=1 \mathrm{yr}$. 
same period (Douglas and Englehart, 1981; Kahya and Dracup, 1993; Schmidt and Luther, 2002; Tolan, 2007). Prevalence and infection intensity of $P$. marinus, the agent of dermo disease, declines at low salinity (Andrews, 1988; Soniat, 1985; Powell et al., 1996) and, consequently, infection intensity follows a four-year cycle in the Gulf of Mexico (Powell et al. 1992; Soniat et al., 2006, 2009). Transmission is sufficiently fast that a delay in population response due to transmission is limited if present at all (Hofmann et al., 1995; Kim and Powell, 1998; Soniat et al., 2006). In the northeast, the North Atlantic Oscillation (NAO) contains an 8-year signal. This signal is primarily manifested as a cycle in winter temperature (Hurrell and van Loon, 1997; Notaro et al., 2006), an important determinant of the dynamics of dermo disease (Quick and Mackin, 1971; Powell et al., 1996; Cook et al., 1998; Ford and Smolowitz, 2007). Consequently, a cycle of approximately eight years is typically present in the dynamics of dermo disease in the northeast (Powell et al., 2008, 2009a; Soniat et al., 2009; Bushek et al., this issue).

Climate cycles may affect species population dynamics in a multitude of ways, from population abundance (e.g., Mullin, 1995; Tunberg and Nelson, 1998; Attrill and Power, 2002; Thatje et al., 2008) to recruitment (Dawe et al., 2000) to contaminant body burden (Wilson et al., 1992; Kim et al., 1999) to parasite prevalence (e.g., Mouritsen and Poulin, 2002; Oliva et al., 2008). In some cases the interaction of disease with host population dynamics is inherently cyclic (Elderd et al., 2008), but in the marine world, climate cycles often serve as inducers of cyclicity in population dynamics. Climate cycles may influence the development of disease resistance by controlling the timing of epizootic mortalities that foster selection. The influence of cycles may be modulated by the relative length of the host's life span relative to the cycle period. Longer life spans may expose a host cohort to several rounds of selection. Shorter life spans may enable some cohorts to avoid increased mortality and hence circumvent selection. In the marine world, climate cycles may exert an important control over animal life span (Powell and Cummins, 1985). For the case of dermo, the average life span of the oyster is strongly influenced by the frequency of epizootics because the increment in mortality rate typically more than doubles the baseline mortality rate (e.g., Powell et al., 2009a). Thus, life span might be anticipated to approximate the period of the climate cycle controlling mortality through the disease.

Cyclicity of epizootics offers one viable explanation for the incongruity between the great promise of disease resistance revealed by genetic analysis through identification of resistant genotypes and its meager deliverance through selection. Here, we employ a genebased population dynamics model configured for the eastern oyster, Crassostrea virginica, to evaluate the influence of climate cycles on the development of resistance to dermo disease. We investigate three cycle periods: a 4-year period typical of ENSO (Cane, 2005; Tolan, 2007; Thatje et al., 2008), an 8-year period typical of the NAO (Bojariu and Gimeno, 2003; Notaro et al., 2006; Soniat et al., 2009), and a 16-yr period of unknown origin that seems to be present in the Delaware Bay time series for the oyster stock (Powell et al., 2009a), but which is reminiscent of the Lunar Nutation cycle of about $18 \mathrm{yr}$ (Gray and Christie, 1983). 


\section{Methods}

a. The model-DyPoGen (Dynamic Population Genetics Engine)

Further details of the model are provided in Powell et al. (2011a,b,c).

i. Model structure and flow. The Dynamic Population Genetics Engine (DyPoGen) is a numerical model which simulates, for this implementation, the genetic structure and population dynamics of Crassostrea virginica. The model can be described as the marriage of three components, a post-settlement population dynamics submodel that contains parameterizations for growth, mortality, and reproduction; a larval submodel that contains parameterizations for larval mortality; and a gene submodel that describes each animal in terms of its genetic structure and that tracks genotype through time from one cohort to the next. Alleles can be lost through drift and, for some, through selection. For the latter, a genotype-phenotype interface interprets genotype in terms of fitness that then influences the post-settlement submodel. This permits the feedback between genotype and phenotype that drives selection.

Many of the processes in the model depend on a random draw. Unless otherwise indicated, a number is drawn from a uniform distribution with a range from 0 to 1 . These uniform deviates $(R)$ are obtained from the pseudo-random generator function $\operatorname{ran} 3^{6}$ described by Press et al. (1986). Whenever a normal deviate $(N)$ is required, the gasdev routine of Press et al. (1986) is used to obtain a random deviate from a zero mean, unit variance normal distribution. Repeat simulations using different sequences of random numbers returned results with only modest variations in scale and trend in initial trials. Consequently, results are provided only for single simulations for each set of parameter values.

ii. Post-settlement population dynamics.

- Sex determination. Oysters are protandric (Kennedy, 1983; Morton, 1990; Guo et al., 1998). Gender is specified by a recessive protandric allele $(P)$ and a dominant male allele $(M)$ (Guo et al., 1998). The homozygous male animal $(M M)$ does not occur. The heterozygote male $(P M)$ acts only as a male. The protandric individual $(P P)$ is male at an early age and converts to female at some later age. Each generation, a protandric male is given the chance to convert to a functional female. A conversion probability was obtained from empirical data from Delaware Bay (Powell et al., 2012) using age-length relationships recorded by Kraeuter et al. (2007). Powell et al. (2012) found that the relationship between the fraction female, $F f$, and age could be modeled as a Gompertz curve (Gompertz, 1825):

$$
F f=\alpha e^{\beta e^{(\gamma \cdot A g e)}}
$$

where Age is the age of the animal in years. Eq. (1) can be used to estimate a probability for any animal changing from male to female based on its derivative:

$$
D f=\frac{d F f}{d A g e}=\alpha \beta \gamma e^{\left((\gamma \cdot A g e)+\left(\beta e^{(\gamma \cdot A g e)}\right)\right)} .
$$

6. Model parameters are shown in typewriter font whereas variables are shown in italics font. 


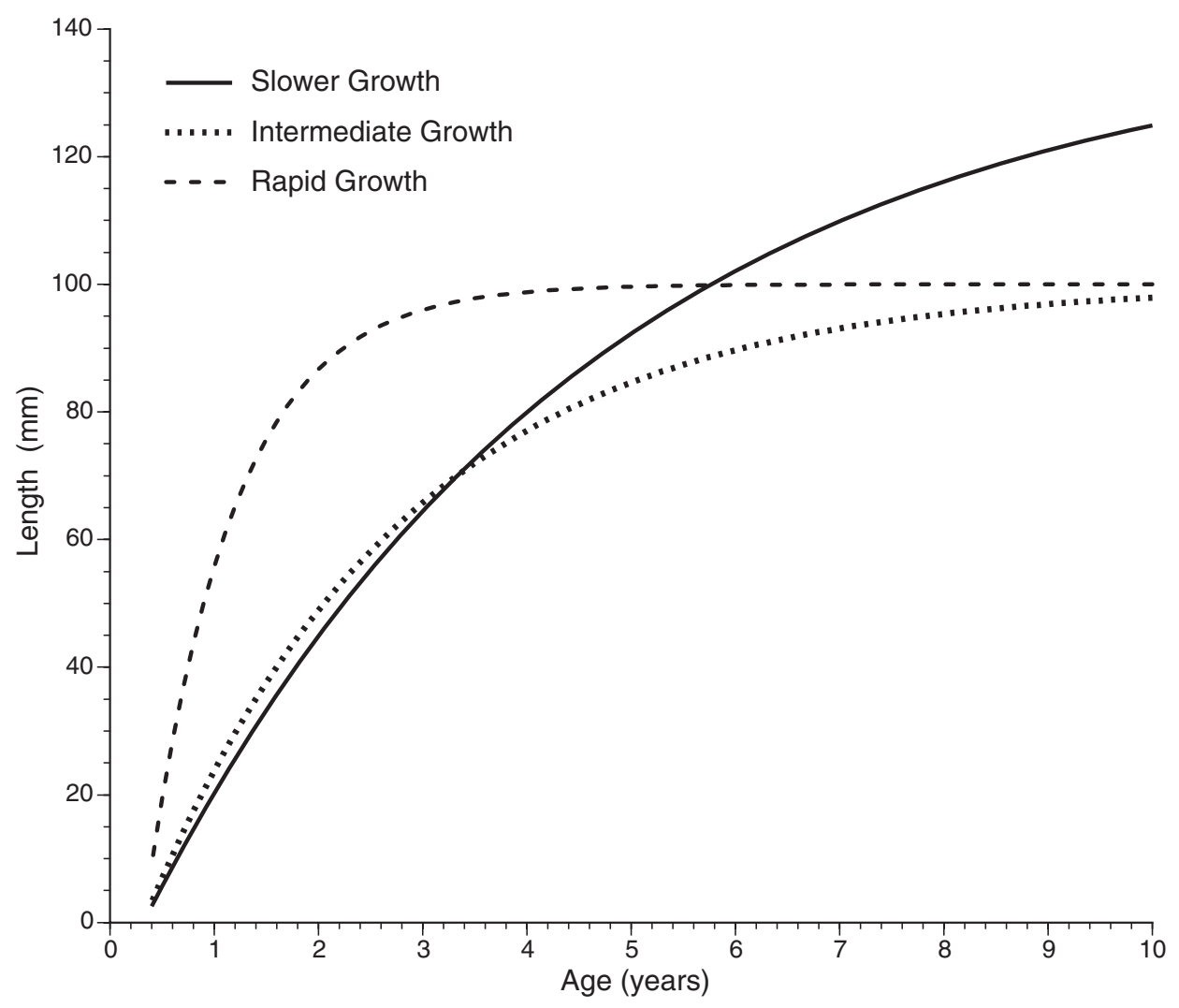

Figure 1. The three von-Bertalanffy curves used. The rapid-growth curve is from Addison (2006) for oysters from Hackberry Bay and Snail Bay, Louisiana. The intermediate-growth and slow-growth curves come from Chesapeake Bay and Delaware Bay populations, respectively.

The probability is then calculated as

$$
P=\min \left(1, \frac{D f}{1-F f}\right)
$$

For the simulations used here, the parameter values for the high-mortality beds in Delaware Bay (for descriptions of bed regions, see Figure 1 in Powell et al., 2008; for mortality trends between bed regions, see Figure 15 in Powell et al., 2011a) have been used: $\alpha=0.79$, $\beta=-3.9, \gamma=0.653$. All oysters that are protandric begin life as male. However, some recruits convert to female prior to first spawning, as appears to be the case in the field (Powell et al., 2012). Due to the age dependency of the probability of sex change, all long-lived protandric individuals eventually become functional females. 
- Reproduction. Each simulated mating season creates a cohort of newly-recruited individuals. With one exception, animals born in one year were assumed not to spawn in the same year, a reproductive pattern typical of all but the most southern climes (Stauber, 1950; Hayes and Menzel, 1981; Kennedy and Krantz, 1982; Barber et al., 1991). The fraction of the population parenting the next generation is derived from a predefined fraction of parents spawning each mating season, FracParents, based upon estimates of effective population number for oysters (Hedgecock et al., 1992; Hedgecock, 1994; He et al., this issue):

$$
\text { FrParents }=\text { FracParent } \mathrm{s} \cdot 10^{(\text {N.FracParentsVar })}
$$

FracParentsVar permits variability to exist in the fraction of parents reproducing. FrParents is used to determine the number of mating pairs as

$$
n \text { Parents }=0.5 \cdot \text { FrParents } \cdot \text { LastAnimal }
$$

where LastAnimal is the count of adult animals in the population.

Potential parents are drawn randomly, without replacement, from a list of all animals to provide $n$ Parents, or until the list of animals is exhausted. Males and females are matched randomly, without replacement, from the parents' lists. During meiosis, each set of haploid chromosomes is obtained by randomly choosing one from each pair of chromosomes. Recombination is implemented by the random choice of a location for each chromosome pair for each parent and the genetic information is crossed over at this point. Then, the chromosome pairs for each parent are separated and one of the two strands is chosen at random for each offspring. The number of offspring produced by each parent is controlled by MaxOffspring which is set at the beginning of the simulation. However, oyster fecundity varies with size (Choi et al., 1993; Hofmann et al., 1994; Kobayashi et al., 1997). Consequently, the number of offspring is affected by parental age through a weight-based von-Bertalanffy process (Fabens, 1965; Mancera and Mendo, 1996; Jensen, 1997) relating size and fecundity to age:

$$
W=W_{\infty}\left(1-e^{-k t}\right)^{b}
$$

where $k$ and $L_{\infty}$ are the von-Bertalanffy parameters and $W_{\infty}$ is obtained from $L_{\infty}$ by the allometric equation relating length to dry weight, $W=a L^{b}$, with $a=0.0003$ and $b=2$. For oysters, weight scales more nearly to the square of the length rather than the more typical cube [compare Froese (2006) to Yoo and Yoo (1973), Powell and Stanton (1985), Harding et al., 2010; for Delaware Bay, few exponentials exceed 2.2 (Powell, unpubl. data)].

Three von-Bertalanffy curves have been used in this study (Fig. 1), covering a range of growth rates typical of oysters in temperate latitudes. The von-Bertalanffy parameters are: for fast growth, parameters were fit from data obtained from oysters in Snail Bay and Hackberry Bay, Louisiana (Addison, 2006), $k=1.2, L_{\infty}=100$; for intermediate 
growth, parameters were obtained for $C$. virginica from the James River in Chesapeake Bay (Mann, pers. comm.), $k=0.4$ and $L_{\infty}=100 \mathrm{~mm}$. For slower growth, parameters for the high-mortality beds of Delaware Bay were obtained from Kraeuter et al. (2007), $k=.23, L_{\infty}=140$. We recognize that the values of $L_{\infty}$ are likely biased low relative to prehistoric populations little affected by fishing or disease. These three cases are representative of literature values that cover a relatively wide range (e.g., Rothschild et al., 1994; Arizpa, 1996; Mancera and Mendo, 1996; Mann and Evans, 2004). Slower growth rates are known from these latitudes [e.g., the low-mortality region of Delaware Bay (Kraeuter et al., 2007)], however these populations typically live under conditions not conducive to Perkinsus marinus proliferation and so are not considered further in this study.

Eq. (6) is applied to fecundity by assuming that oyster spawn is a standard fraction of biomass (Hofmann et al., 1992, 1994). Hence, the fecundity equivalent of $W_{\infty}$, MaxOffspring, is scaled to animals of a range of sizes by the von-Bertalanffy correction factor, AgeFactor, defined as

$$
\text { AgeFactor }=\left(1-e^{-k\left(a g e-a g e_{\circ}\right)}\right)^{b}
$$

AgeFactor is the same for males and females of the same age; however, the partner producing the fewest gametes determines the total fecundity. The number of eggs produced is

$$
n O f f=1+\left(2^{(2 N \eta)} \cdot \text { AgeFactor } F \cdot \text { MaxOff spring }\right)
$$

and the number of sperm produced is

$$
n O f f M=1+\left(2^{(2 N \eta)} \cdot \text { AgeFactorM } \cdot\left(\text { MaxOff } \operatorname{spring} \cdot 2^{11}\right)\right)
$$

where $\eta$ takes the value 0 or 1 so that variability can be imposed when desired and the factor $2^{11}$ represents the greater number of sperm made from a given amount of gonadal mass [compare Dong (2005) and Gallager and Mann (1986)]. The value of two multiplying $N$ approximates the factor of two difference in spawning potential observed in the genus Crassostrea between, for example, C. virginica and C. gigas (Héral and Deslous-Paoli, 1983; Choi et al., 1993, 1994; Kang et al., 2003; Ngo et al., 2006). Fertilization is assumed never to be sperm-concentration limited (Powell et al., 2012).

- Adult mortality. Adult mortality is specified as age-dependent. Although juvenile mortality is high in bivalves, this portion of mortality was subsumed into larval mortality, as the purpose of the simulations was to examine the influence of mortality factors acting on sexually mature animals. Age-dependent mortality is an inherent attribute of oyster populations impacted by dermo disease (Hofmann et al., 1995; Powell et al., 1996; Harding et al., 2010) and is characteristic of some other bivalves such as hard clams, Mercenaria mercenaria (Hofmann et al., 2006; Kraeuter et al., 2008). Whether mortality in oyster populations existing prior to the onset of disease or human exploitation was age-dependent is unknown. However, the mismatch in life expectancy based on observed adult mortality 
rates prior to disease onset of $10 \%$ to $13 \%$ per year (Powell et al., 2008, 2009a) inferred from an assumption of constant mortality (e.g., Hoenig, 1983) and the few pertinent direct estimates of adult age frequency (e.g., Harding et al., 2008) supports such a formulation, as the mortality rate inferred from surveys prior to disease onset would predict the observation of older animals than are observed.

Consequently, the probability of dying is derived from the age of the animal according to the formulae:

$$
A M=\text { AvgAgeMort }-((1-\text { FitFac }) \cdot \text { dAvgAgeMort } \cdot \text { TimeFac }),
$$

$$
A S M=\text { AvgSpreadMort }-((1-\text { FitFac }) \cdot \text { dAvgSspreadMort } \cdot \text { TimeFac }),
$$

and

$$
P=.5\left[1+\tanh \left(\frac{A g e-A M}{A S M}\right)\right]
$$

where $P$ is the probability of death, AvgAgeMort is the average age of mortality ( $P$ is 0.5 at this age), and AvgSpreadMort controls how rapidly the mortality approaches 1 . An increase in mortality, such as might occur with the onset of dermo disease, is introduced by non-zero values for dAvgAgeMort and dAvgSpreadMort. FitFac is a fitness factor that permits this increase in mortality to be modulated by the individual's genotype as described later. TimeFac imposes a periodicity to the mortality rate:

$$
\text { TimeFac }=0.5\left(1 .-\cos \left(\frac{2 \pi S Y}{\text { MortPeriod }}\right)\right)
$$

where MortPeriod is the cycle period in years and SY is the simulation year. Note that Eq. (13) stipulates that cyclic mortality occurs only with non-zero values for dAvgAgeMort and dAvgSpreadMort. That is, the pre-disease natural mortality rate specified by AvgAgeMort and AvgSpreadMort is assumed to be noncyclic. Whether mortality rates in undiseased oyster populations are influenced by climatic cycles is unknown, as time series of such populations are insufficient to provide empirical guidance.

iii. Larval mortality. Larval survival is controlled by an estimated population reproductive capacity which depends on MaxOffspring, nParents (the number of parent pairs), and LastAnimal. The estimated reproductive capacity, standardized to the number of individuals is

$$
\text { ReprPerAdult }=\frac{\text { MaxOff } \mathrm{spring} \cdot n \text { Parents }}{4 \cdot \text { LastAnimal }}
$$

where the factor of 4 includes the average of the uniform random deviates $(0.5)$ and the fact that the number of offspring per parent is one-half of the number of offspring per female. 
The probability of a larva surviving is

$$
\text { LarvalSurv }=(.5+1.5 R) \frac{\text { CarryCapacity }}{4 \cdot \text { ReprPerAdult } \cdot \text { LastAnimal }}
$$

where CarryCapacity imposes a logistic process in which average recruitment per adult declines as population abundance increases with respect to the environmental carrying capacity; thereby limiting population expansion at high abundance. A compensatory relationship between broodstock and recruitment has been identified in a number of molluscan stocks (e.g., Hancock, 1973; Peterson and Summerson, 1992; Kraeuter et al., 2005), including oysters (Powell et al., 2009c), and the ability of oysters to filter water more rapidly than its resupply generating food limitation downstream (Wilson-Ormond et al., 1997) provides a theoretical basis for this expectation.

The probability of death for each larva is calculated as

$$
P=1-\text { LarvalSurv }
$$

For a random draw, if $R<P$, then the larva dies.

\section{iv. Genetic structure and fitness}

- Model initialization. Each animal is specified to have 10 chromosome pairs (Wang et al., 1999, 2005), each with 4 genes, each with 2 alleles. Thus, each animal is specified by 40 genes and 80 alleles and the genotypes permitted for each locus are $A A, A B$, and $B B$. To initiate a simulation, an initial population numbering NewAnimals is created with a biased-random genetic structure. Alleles for loci not affecting disease resistance are assigned to the $A$ or $B$ genotype randomly. Alleles on loci identified as potentially conferring dermodisease resistance are assigned with a 1:9 $A: B$ probability. Thus, initial allele frequency for alleles conferring disease resistance, all given the $A$ genotype, approximated $10 \%$. This low allele frequency invokes the assumption that such alleles are rare in naïve populations, possibly due to the likelihood that such alleles are inherently deleterious if the disease is not present (e.g., Cotter et al., 2004; Detilleux, 2005; Zbinden et al., 2008; Hasu et al., 2009; Duffy and Forde, 2009).

Guo (unpubl. data) identified fourteen loci with alleles that may confer some degree of resistance to mortality from dermo disease. These loci were identified as having significant shifts in genotype frequency within families after disease-caused mortality. The exact mechanisms are unknown; however, we assume each directly affects disease resistance rather than, for instance, influencing a more general trait related to, as examples, growth rate or production that might indirectly affect the relationship of parasite and host (Powell et al., 1996; Waaij et al., 2000). The fourteen are major loci supported by two or more closely linked markers, and likely represent an unknown, but important, proportion of all loci involved in disease resistance. Certain of these alleles may confer a greater increment in survival than others; however, the data presently available are insufficient to provide more than a crude and relatively uncertain ranking. For the purposes of this study, the importance 
Table 1. The allele fitnesses (PhysioFuncWeight) for each of the fourteen loci associated with resistance to dermo disease. In each case, the $A A$ genotype is given a value of 1.0 and the remaining genotypes are valued relative to that ranking (Guo, unpubl. data). Chromosomes are numbered according to Wang et al. (2005). Locus number is simply an ordinal assignment. Position on the chromosome was assigned for convenience to site 1 for a single locus contributing to disease resistance, positions 1 and 3 for dual loci, and positions 1, 2, and 3 or 1, 2, and 4 for a triplex of loci. Adult fitness is defined between 0 and 1 , inclusive, by standardizing the maximal adult fitness, all participating loci homozygous $A A$, to 1.0 and the minimal adult fitness, all participating loci homozygous $B B$, ignoring underdominance, to 0.0 . Thus some rare and unlucky individuals might have an adult fitness $<0$.

\begin{tabular}{cccccc}
\hline & & Assigned Position & \multicolumn{3}{c}{ Relative Fitness } \\
\cline { 4 - 6 } Locus & Chromosome & on Chromosome & $A A$ & $A B$ & $B B$ \\
\hline 1 & 1 & 1 & 1.0 & 0.424 & 0.152 \\
2 & 2 & 1 & 1.0 & 0.726 & 0.506 \\
3 & 3 & 1 & 1.0 & 0.556 & 0.162 \\
4 & 4 & 1 & 1.0 & 0.554 & 0.390 \\
5 & 4 & 3 & 1.0 & 0.561 & 0.325 \\
6 & 7 & 1 & 1.0 & 0.584 & 0.289 \\
7 & 7 & 2 & 1.0 & 0.596 & 0.289 \\
8 & 7 & 4 & 1.0 & 0.390 & 0.628 \\
9 & 8 & 1 & 1.0 & 0.579 & 0.335 \\
10 & 8 & 3 & 1.0 & 0.566 & 0.089 \\
11 & 9 & 1 & 1.0 & 0.141 & 0.339 \\
12 & 9 & 3 & 1.0 & 0.385 & 0.179 \\
13 & 9 & 2 & 1.0 & 0.531 & 0.439 \\
14 & 10 & 1 & 1.0 & 0.528 & 0.504 \\
\hline
\end{tabular}

of this information is to establish (1) that a rather large number of alleles may be involved in the selection process and (2) that these loci are distributed among the majority of the chromosomes (Table 1).

- Definition of fitness. Ultimately, fitness of any potential parent is established by the number of progeny that live to reproduce. Since the fraction of the population successfully spawning is small [Eq. (4)] and post-settlement mortality rate is often high, many recruits fail to spawn successfully before they die. Discounting the probabilistic aspects of the model, the factors that control the number of progeny that reproduce include the growth rate that controls lifetime spawning potential by influencing size at age and the mortality rate that is age dependent. The first is imputed to the model by means of a von-Bertalanffy process. The second, in this study, is influenced by selection. For simplicity, we use adjectival modifiers to the term 'fitness' to refer to three subsets of this overall process. The term 'allele fitness' is applied to the contribution of any specific locus (relative fitness in Table 1) to 'adult fitness'. The term 'adult fitness' refers to the arithmetic average of the genetic complement of loci that influences the probability of death at age for a given animal. The term 'population 
fitness' refers to the arithmetic average of the adult fitness values for the individuals in the population.

- Implementation of fitness. The value for allele fitness for each genotype potentially present at a locus, $A A, A B$, or $B B$, is provided by the first, second or third, respectively, value of PhysiofuncWeight (Table 1). Each locus on a chromosome pair is assigned a set of allele fitnesses through the array PhysiofuncClass. Thus, one locus may be characterized by dominance and another underdominance, for example. For these simulations, the fourteen loci have been assigned allele fitnesses as described in Table 1, based on the designation of $A$ for the allele conferring disease resistance and the designation of $B$ for the remaining alleles. Each is given a weight relative to 1.0, which is assigned to the $A A$ homozygote, in keeping with the earlier caveat that only the relative ranking of effect on disease resistance among genotypes can now be assigned with any degree of confidence. Note that most of these loci are characterized by some degree of dominance; however two are characterized by underdominance (loci 8 and 11) and several are characterized by a limited differential between the $B B$ and the $A B$ genotype (e.g., loci 13 and 14, Table 1). The array Fitnessclass then determines which of the genes influences adult fitness. Positions of each such gene on each chromosome are reported in Table 1.

Thus, adult fitness is determined for each individual as follows. Each allele pair at a locus is identified as $A A, A B$, or $B B$. The entry for that locus in Fitnessclass identifies whether it is among those potentially conferring disease resistance and the entry in PhysiofuncClass identifies which set of allele fitnesses to use; the PhysiofuncWeight for the allele pair gives the value contributing to adult fitness by that locus. The adult fitness for the animal is determined as the average of the fourteen values from each of the fourteen loci conferring disease resistance. Most oyster loci have more than two alleles (Launey and Hedgecock, 2001; Wang and Guo, 2007). For these simulations, we assume that only one of these alleles is associated with disease resistance, so that a two-allele configuration can be used with the second allele representing the host of alleles having no influence on disease resistance. We assume no epistasis, having limited information to the contrary (e.g., Sokolova et al., 2006), though epistasis is a common occurrence in Crassostrea (Hedgecock et al., 1995, 1996).

In some cases, the simple average of the maximum or minimum values of allele fitness for the designated loci may define a range narrower than 0 to 1 , inclusive. From Table 1, an animal with all $B B$ genotypes at the 14 loci would have an adult fitness value well above 0 , for example. This is an inherent outcome of the relative rankings provided by genetic analyses (Guo, unpubl. data). To retain the important distinction between the most and least fit animals within a specified 0-to-1 range for adult fitness, the minimal and maximal fitness values obtained from sums of the individual fitness values for each of the designated alleles are standardized to values of 0 and 1, respectively, and any value between 0 and 1 standardized within the 0 -to- 1 continuum by interpolation. The final adult fitness for each animal, then, has a value between 0 and 1, inclusive. We recognize that an animal with $A B$ genotype at the two loci showing underdominance and otherwise $B B$ would have an adult 
fitness value below zero; such rare animals are re-defined with an adult fitness of zero for convenience.

- Genotype-phenotype interface. In simulations reported here, the survival of the adult animal is affected by a fitness value, FitFac, as specified in equations (10)-(11). Each simulation is referenced against a base case configured for a mortality rate thought to be characteristic of oyster populations before the onset of significant mortality by dermo disease. This mortality rate is of the order of $10 \%$ to $15 \%$ of the adult population per year (Powell et al., 2008, 2009a). Base cases were run for 200 generations with one cohort born per year to permit drift to modify allele frequencies from the initial state. The population after 200 generations (200 years) is defined as the naïve population. Dermo disease is introduced in generation 201 by increasing the value of dAvgAgeMort and dAvgSpreadMort in equations (10) and (11) from zero to some value between 0 and the value of AvgAgeMort and AvgSpreadMort. This increases the rate of adult mortality to the degree permitted by the fitness value of the individual as determined by FitFac. An example is shown in Figure 2 in which a naïve population with a yearly mortality of about $13 \%$ of the stock without the disease (labeled $\mathrm{F}=1$ in Fig. 2) is exposed to a yearly mortality of about $25 \%$ of the stock at FitFac $=0$ (labeled F=0 in Fig. 2). After developing complete resistance to the disease at FitFac $=1$, the stock attains the natural mortality rate of the unexposed naïve population (labeled $\mathrm{F}=1$ in Fig. 2).

\section{b. Statistics}

Generation time was calculated after Felsenstein (1971) with one modification. We defined all $P P$ males as immature females and all $P P$ females as senescent males. Then, mean generation time $T$ is:

$$
T=\sum_{i=0}^{n} l_{i, g} b_{i, g} i .
$$

where $i$ is animal age in years, $n$ is the maximum age achieved by animals in the cohort, with one cohort per year implicit. The probability of survival to age $i$ for animals in any given cohort $g, l_{i, g}$, is defined as

$$
l_{i, g}=\frac{N_{i, g}}{N_{0, g}},
$$

where $N_{0}$ is the initial number of animals in the cohort, and $N_{i}$ is the number of individuals surviving at age $i$. The number of offspring per female of age $i$ and cohort $g, b_{i, g}$, is defined as

$$
b_{i, g}=\frac{O_{i, g}}{N_{i, g}},
$$

where $O$ is the number of recruited offspring produced by animals of age $i$ in cohort $g$. 


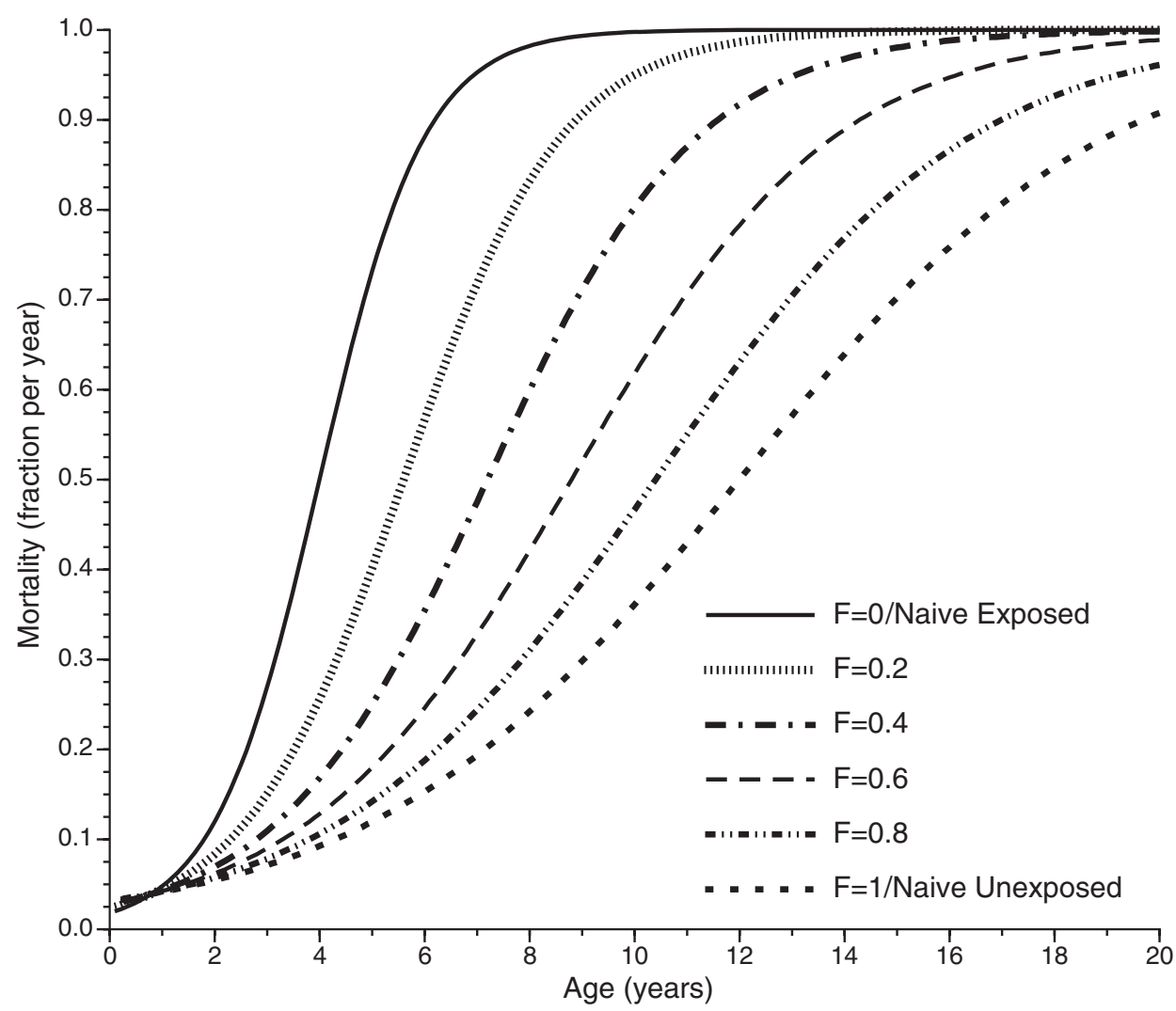

Figure 2. An example of the mortality trends with age for adult fitness varying by 0.2 units from a fitness of 0 to a fitness of 1 . The fitness-of -0 case ( $F=0$ or naïve exposed) yields a population mortality rate of about $25 \%$. The fitness-of -1 case $(\mathrm{F}=1$ or naïve unexposed) yields a population mortality rate of about $13 \%$.

\section{c. Simulation constraints}

Simulations of more than 200 generations following disease onset were deemed unnecessary as simulations of this length proved to be sufficient to reveal how adult fitness, determined by changes in adult mortality, influenced genotype frequency in the population. In some cases, a stable ending genotype frequency was obtained; in other cases, the trajectory for future selection was well established. Each case was initialized by a 200 -year simulation without disease so that allele frequencies varied from the original 50:50 or 10:90 $A: B$ ratio prior to disease onset. Carrying capacity was set so that population abundance remained high enough that genetic drift never resulted in the loss of neutral alleles during these initial 200 generations. Parameter values varying by simulation are summarized in Table 2. 


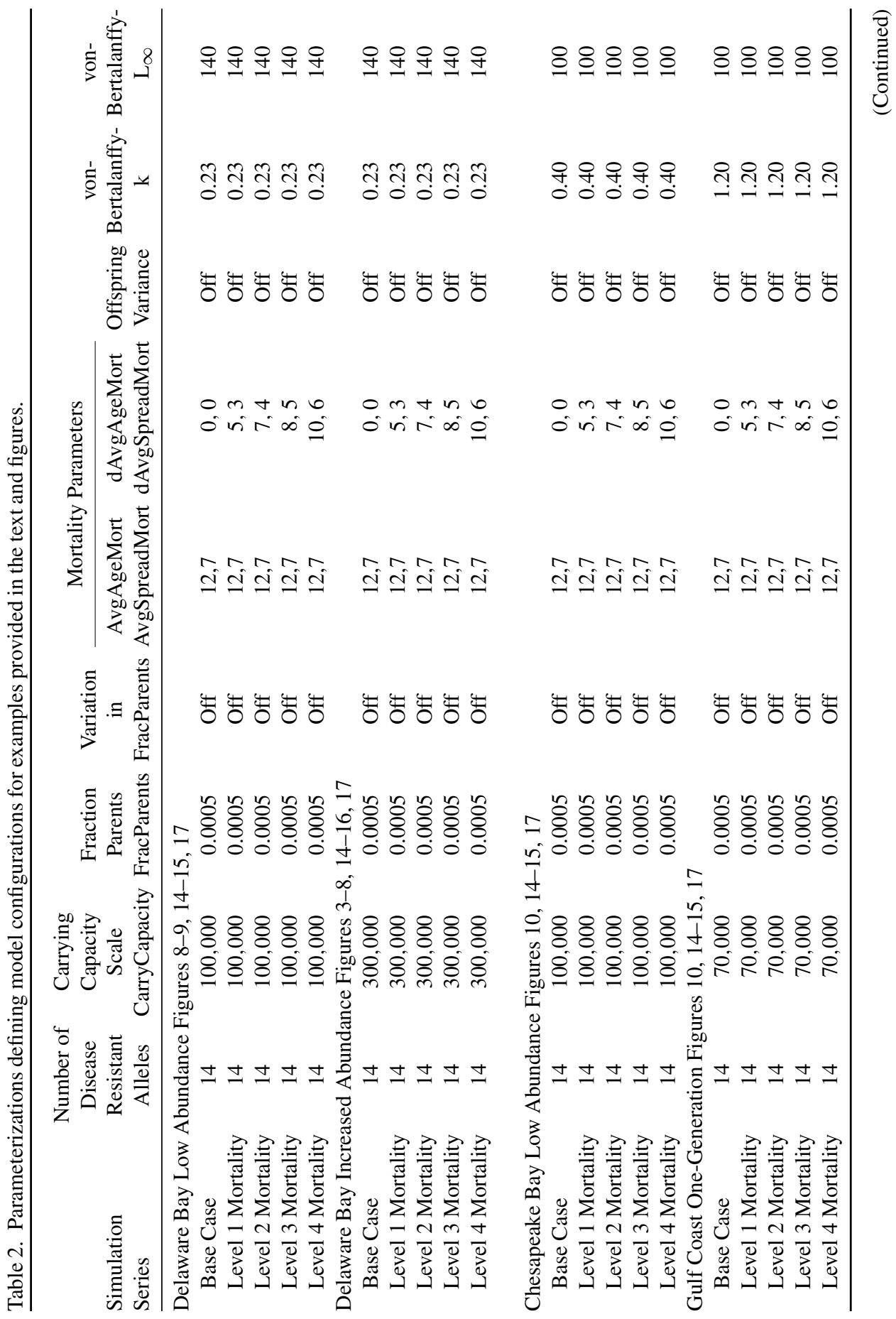




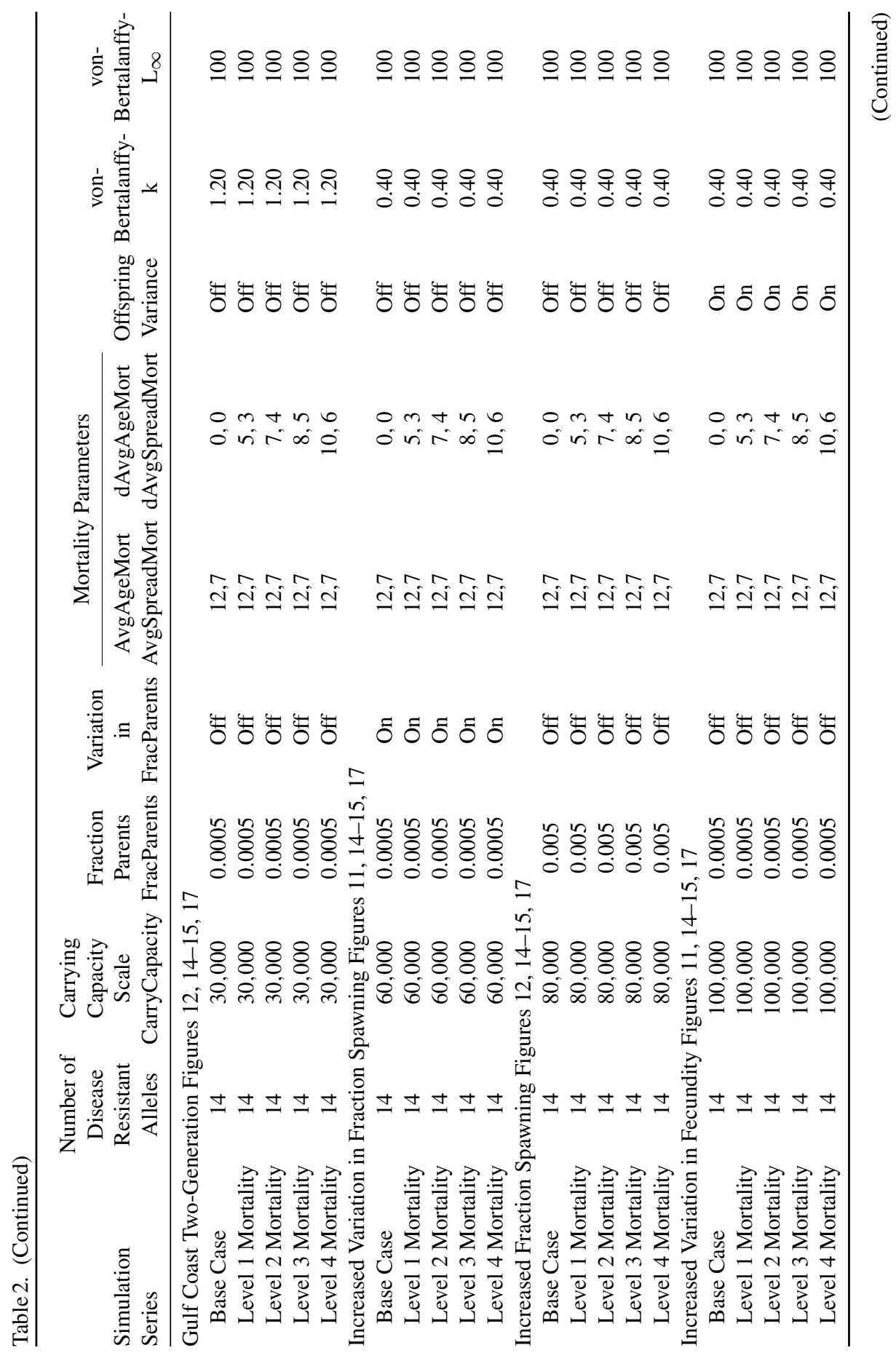




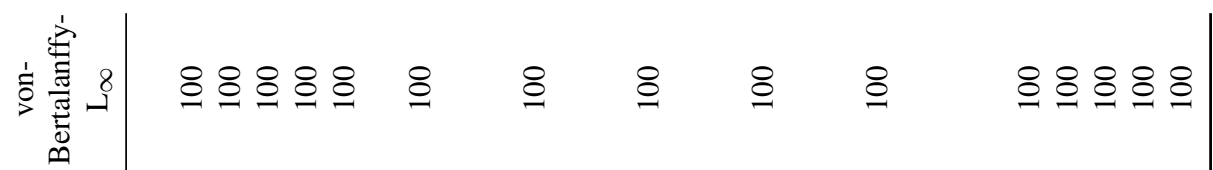

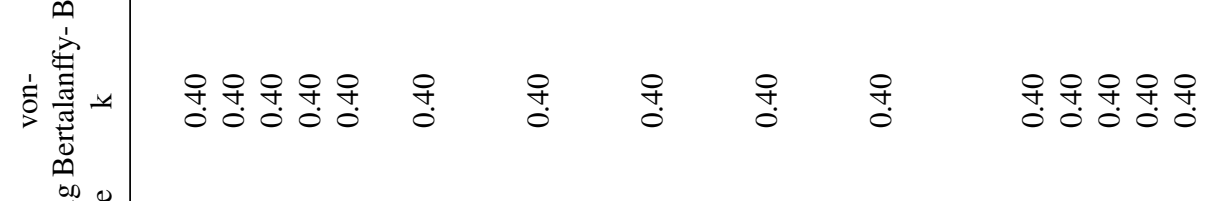

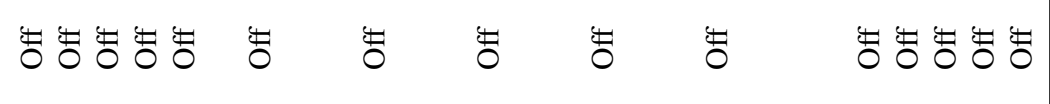

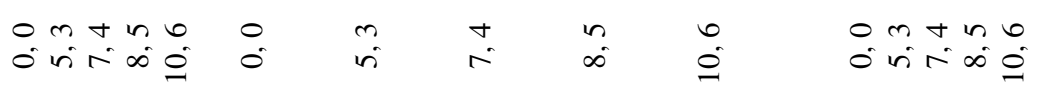
$\hat{I} \hat{I} \hat{I} \hat{I} \bar{I} \quad \hat{I} \quad \hat{I} \quad \hat{I} \quad \hat{I} \quad \hat{I} \hat{I} \hat{I} \hat{i} \hat{I}$

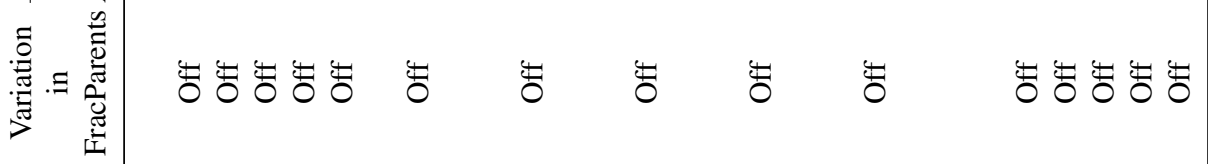

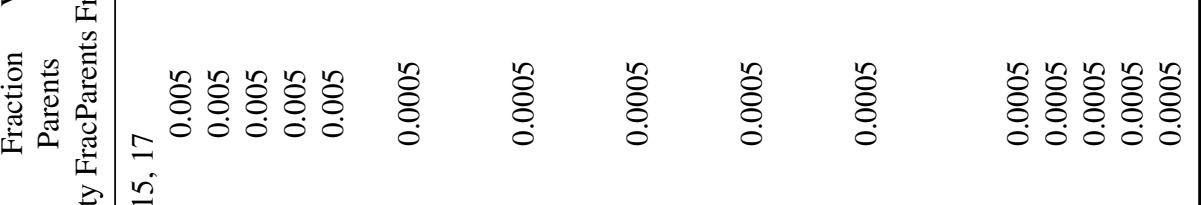

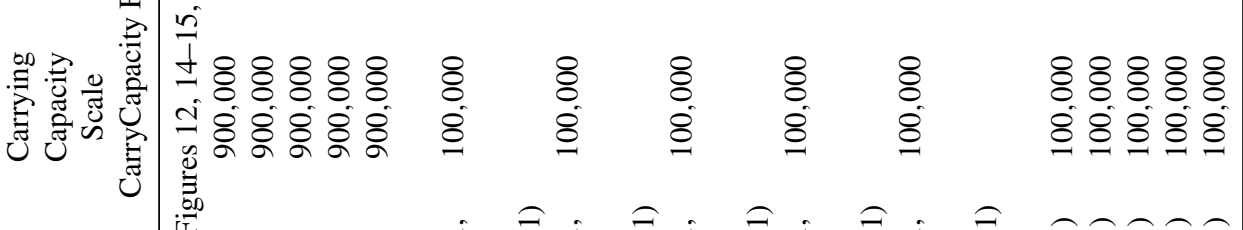

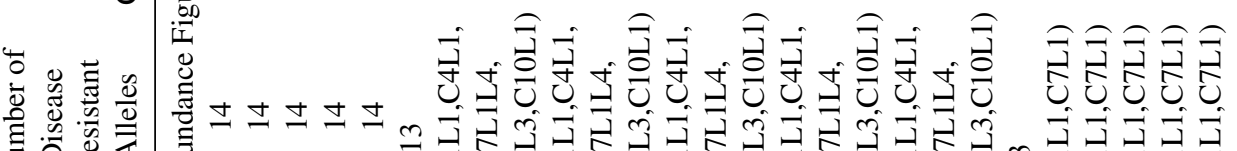

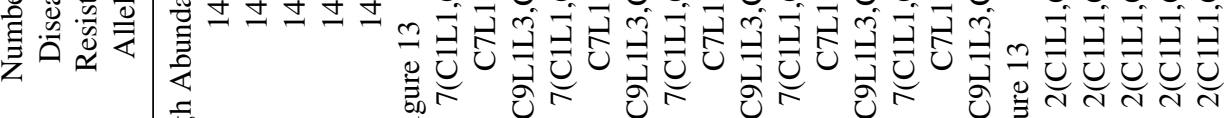

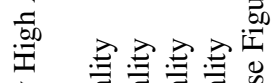

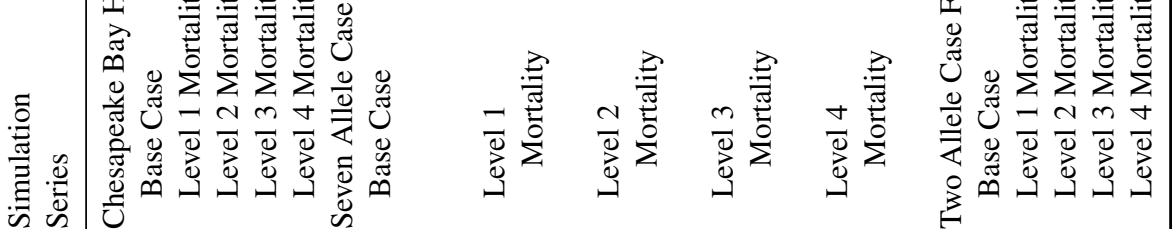




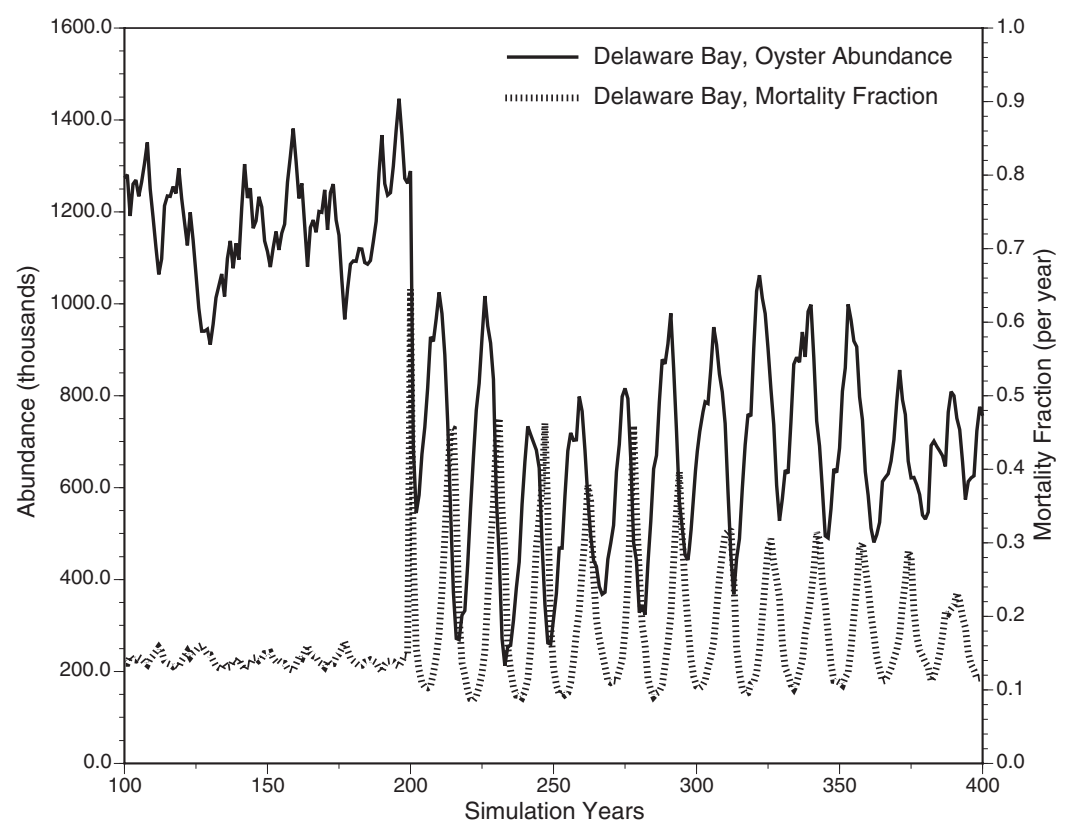

Figure 3. The time series of oyster abundance and mortality, represented as the fraction dying each year, for the Delaware Bay Increased Abundance case with disease pressure imposed at the highmortality level and with a 16-year cycle (Table 2).

\section{Results}

a. Influence of cyclic mortality on population dynamics: a base case

We first examine the influence of cyclic mortality on an oyster population in Delaware Bay challenged in Year 201 with dermo disease increasing mortality by a factor over three (Table 2, Delaware Bay, Increased Abundance). For clarity, we impose the disease with a 16-year cycle. This Delaware Bay case shows a stable population of about 1,200,000 individuals over the first 200 years during which dermo disease was not present. The population has a mortality rate consistent with populations unencumbered by disease of about $13 \%$, congruous with observations reported by Powell et al. $(2008,2009$ a) for the 1950s prior to the onset of disease (Fig. 3, years 1-200). No alleles are lost over the first 200 generations. Allele frequency varies moderately with drift (Fig. 4). The naïve population in Year 200 contains animals with a range of values of low adult fitness with the expected mode of 0.1 based on the initial frequency of alleles conferring disease resistance of $10 \%$. Very few animals exceed an adult fitness of 0.3 on a 0 -to- 1 scale (Fig. 5). Such a population would be expected to be susceptible to epizootic mortality upon onset of a new disease challenge. 


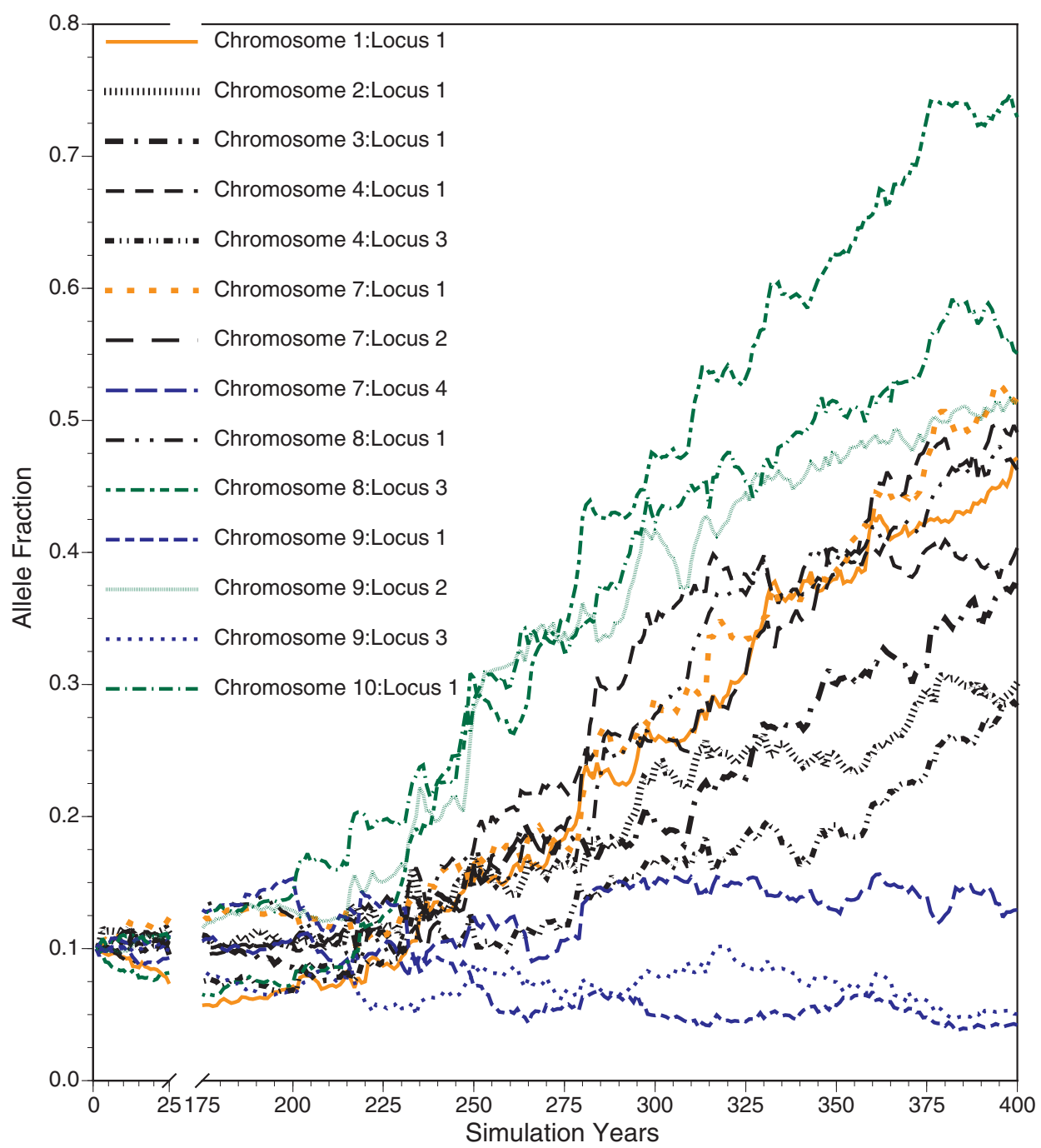

Figure 4. Trajectories for the fourteen alleles conferring disease resistance for the Delaware Bay Increased Abundance case (Table 2). Dermo disease was not present in the first 200 years; during this time these alleles drifted as neutral alleles. Selection for disease resistance began in year 201. Genotype contributions to disease resistance are given in Table 1. Alleles reaching highest frequencies are in green. Alleles with lowest frequencies, two of which are the two alleles showing underdominance, are in blue. Alleles used for two-allele simulations are in orange.

Dermo-induced epizootic mortality is inherently modulated by the local environment, particularly the late summer temperature and salinity (Andrews, 1988; Powell et al., 1996; Ragone Calvo et al., 2001). Thus, we considered two levels of mortality at the onset of disease, interpretable as relative measures of the virulence of the pathogen or 


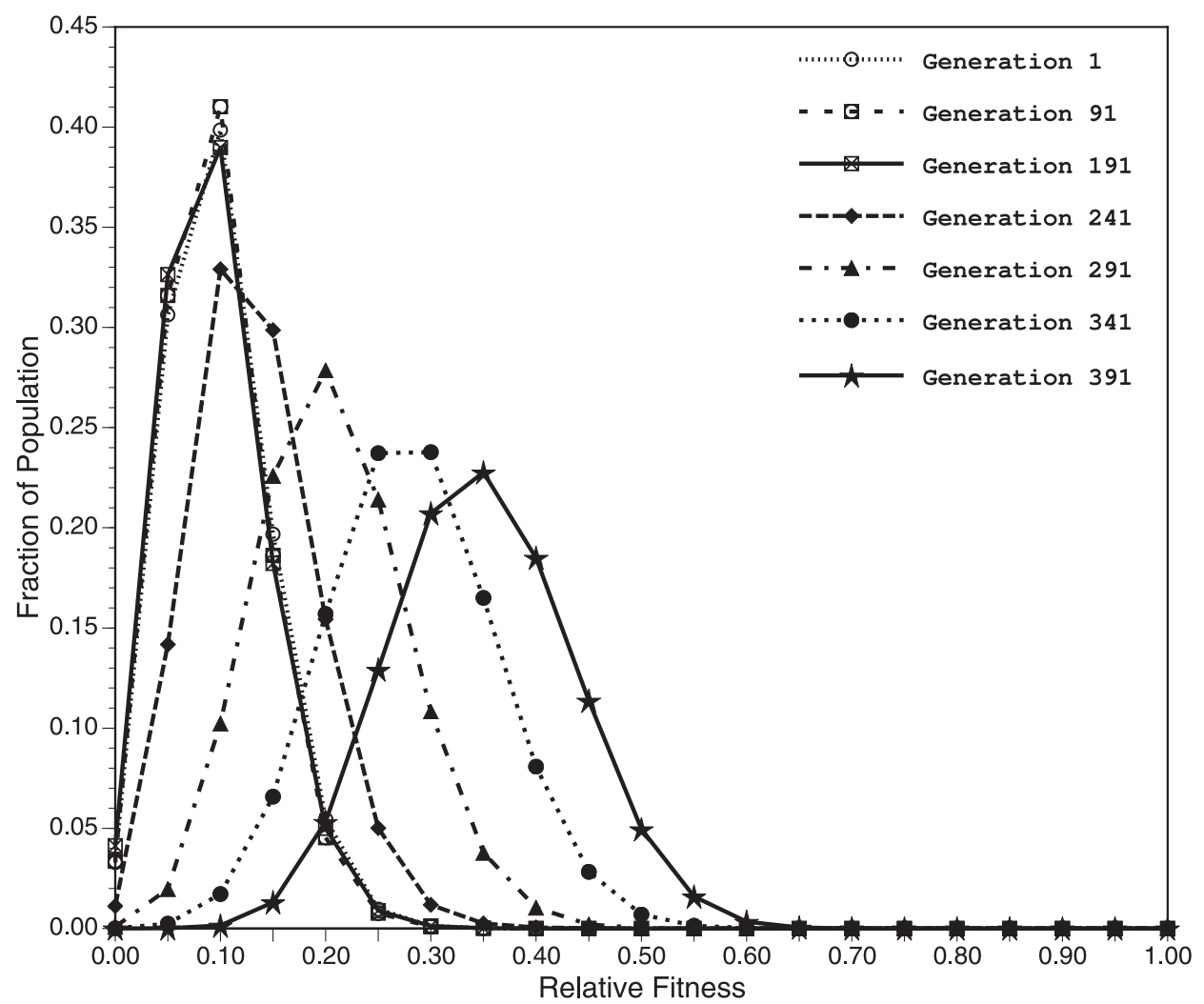

Figure 5. Frequency of adult fitness values for the Delaware Bay Increased Abundance case in which disease pressure was imposed at the high-mortality rate and with a 16-year cycle (Table 2). Generations 1, 91, and 191 are prior to the onset of disease. Generations 241, 291, 341, and 391 follow the onset of disease. Alleles conferring disease resistance were allowed to drift without selective advantage for the first 200 generations.

conduciveness of the environment: $\sim 40 \%$ and $\sim 25 \%$ of the population yearly at cycle apogee (Figs. 3, 6). These will be referred to as high-mortality and moderate-mortality levels, respectively, hereafter. The moderate-mortality case is representative of epizootic mortality rates often observed in Delaware Bay (Powell et al., 2008, 2009a). The highmortality case is a conservative value for the Gulf of Mexico (Mackin and Sparks, 1962; Mackin and Hopkins, 1962) and a level observed in the initial epizootics after onset of dermo disease in the highest mortality-regions of Delaware Bay (Powell et al., 2008, 2009a, 2011a). Chesapeake Bay mortality rates also fall within the moderate-to-high mortality range (Andrews and Hewatt, 1957; Burreson and Ragone Calvo, 1996; Mann et al., 2009). Simulations supporting Figures 3-5 were conducted with the higher level of mortality. 


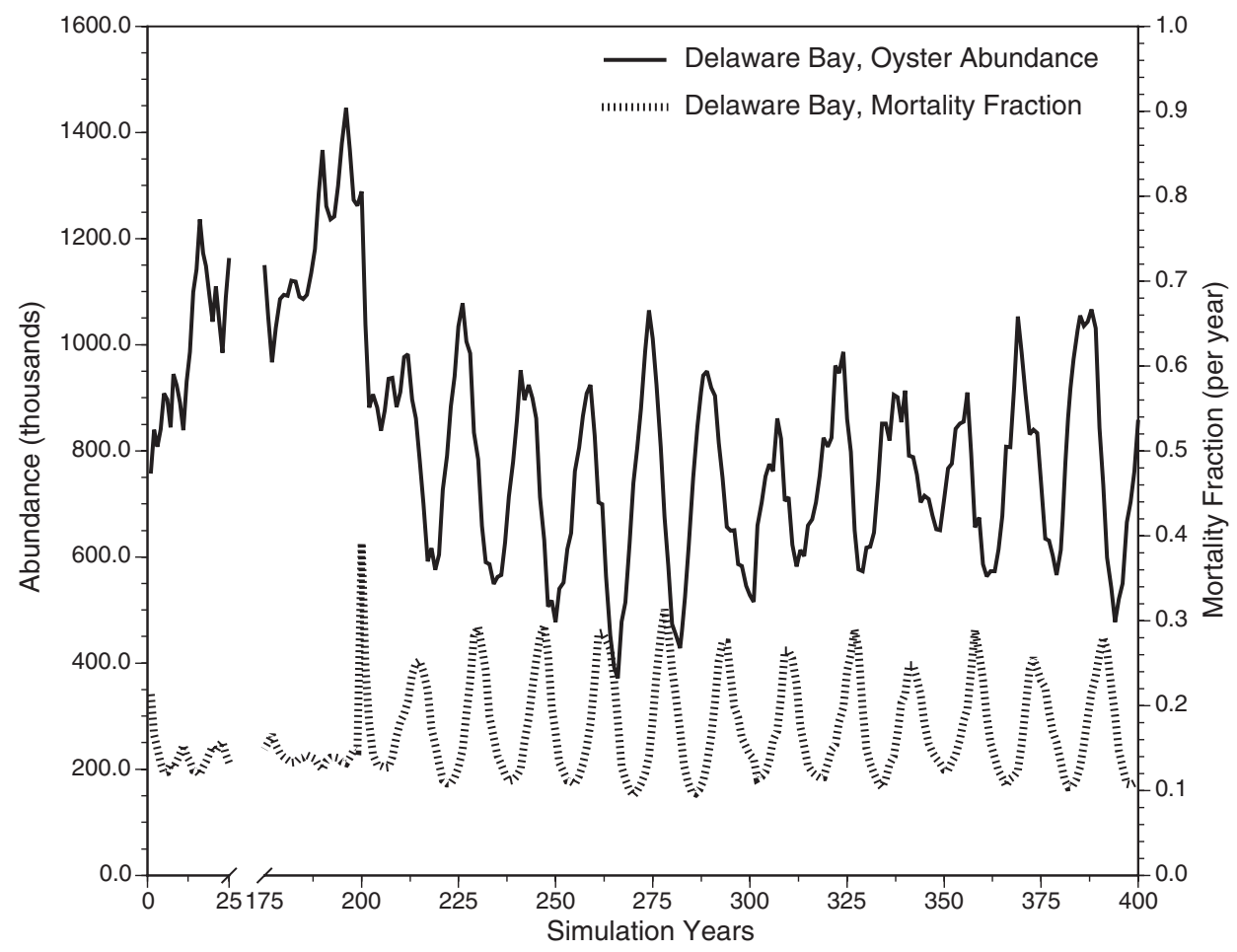

Figure 6. The time series of oyster abundance and mortality, represented as the fraction dying each year, for the Delaware Bay Increased Abundance case with disease pressure imposed in Year 201 at the moderate-mortality level and with a 16-year cycle (Table 2).

At Year 201, disease enters the population with a periodicity of 16 years. Population abundance declines and tends to vary from a nadir of 400,000 to 600,000 to an apogee of about $1,000,000$. The population contracts as disease pressure increases mortality rate to about $40 \%$ per year and expands as lessoning disease pressure returns mortality rate to pre-disease levels. Most alleles conferring disease resistance increase in frequency at the onset of disease in Year 201; a few are unaffected or modestly decrease (Fig. 4). Among the three responding little or not at all are the two loci displaying underdominance (loci 8 and 11, Table 1). The third is on a chromosome with such a locus (locus 12). After disease onset, except when alleles reach high frequency, alleles conferring disease resistance drift lower during the cycle trough and increase in frequency during the cycle crest. This progression-regression behavior slows the development of disease resistance. Adult fitness of the population increases over the 200 generations following the onset of disease, achieving a modal adult fitness of about 0.35 , with most of the population falling between 0.25 and 0.45 (Fig. 5). A few animals reach a value of 0.6 on a 0 -to- 1 scale. 


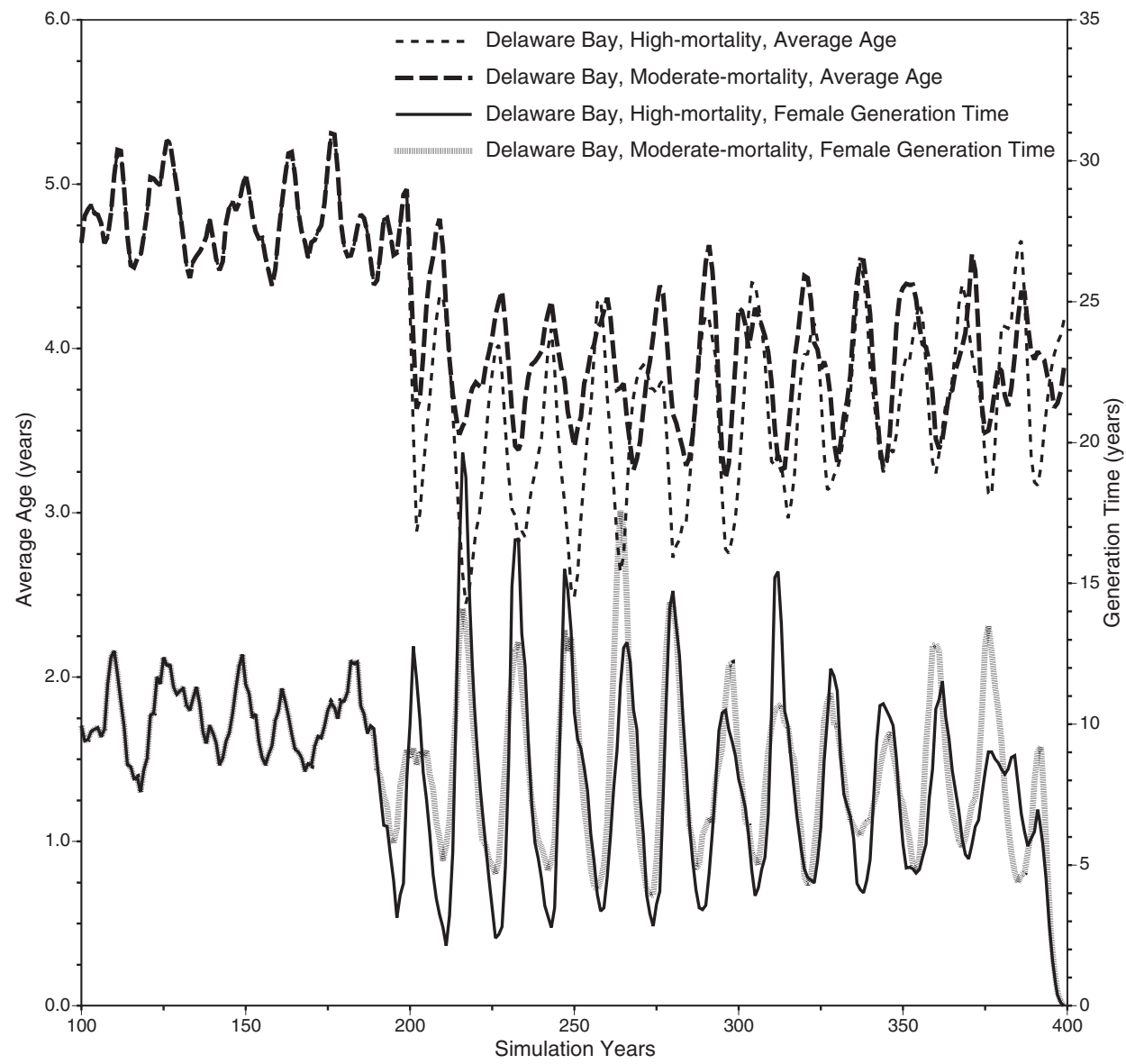

Figure 7. Comparison of average age and female generation time following the onset of disease in Year 201 for the moderate-mortality and high-mortality conditions with a 16-year disease cycle, for the Delaware Bay Increased Abundance case. Protandric males were defined as immature females for calculation of female generation time.

Both the high and moderate mortality rates result in populations that decline in abundance upon onset of the disease with the expected greater decline at cycle apogee ${ }^{7}$ for the higher mortality rate (Figs. 3, 6). In both cases, population average age declines (Fig. 7). In the moderate-mortality case, average age drops from about 5 years to less than 4 years at cycle apogee; for the high-mortality case, the decline reaches less than 3 years at cycle apogee. Female generation time falls from about 10 years in the population prior to the

7. Note that cycle apogee for disease influence and mortality nearly equates with cycle nadir for abundance; all references to cycle periodicity will refer to the periodicity of mortality rate, and therefore will be nearly diametric to cyclic behavior inferred from e.g., abundance and population average age. 


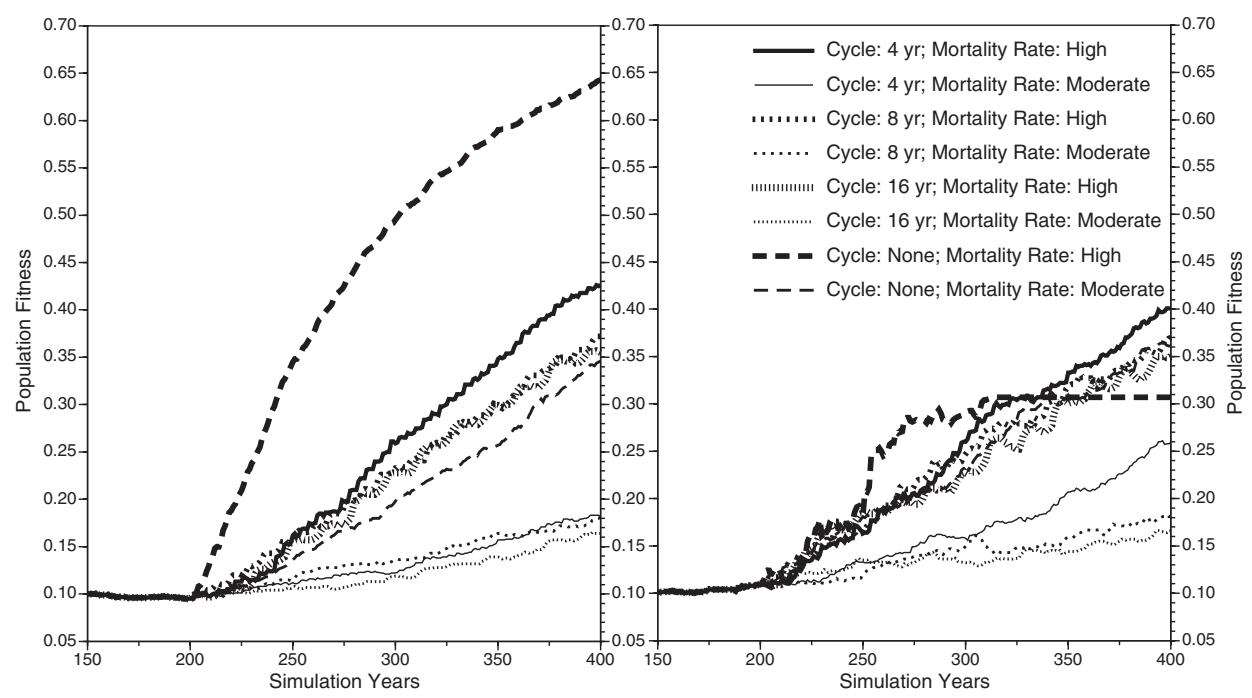

Figure 8. Population fitness for the Delaware Bay Increased Abundance and Low Abundance cases for two levels of disease intensity and commensurate population mortality, three cycle periods, and the absence of periodicity (Table 2). The naïve, unexposed case is shown for Years 150-200. The two levels of disease, and the onset of cyclic mortality when specified, began in Year 201. Fitness ranges from 0 to 1 . Note that the y-axis reaches only 0.7 .

onset of disease to about 5 years at cycle apogee for the moderate-mortality case; for the high-mortality case, generation time falls near 3 years at cycle apogee (Fig. 7). Thus, the disease substantively modifies population dynamics, converting a classic bet-hedger (Stearns, 1976) into something more akin to an r-selected species (Stearns, 1976; Parry, 1981), though iteroparity remains the standard condition.

\section{b. The influence of cycles and population abundance: Delaware Bay cases}

Simulations were conducted for the moderate mortality rate and the high mortality rate for cycles of 4-year, 8-year, and 16-year periodicities. Each was compared to the case in which the disease was continuously present, most of which were considered in more detail in Powell et al. (2011a). Abundance was varied by a factor of about three to evaluate the influence of drift on disease-resistant alleles.

Disease-resistance develops faster at the higher mortality rate and without cyclic behavior by the disease, if drift exerts a negligible influence (Fig. 8). For the higher level of disease mortality, oysters exposed to a 4-year cycle increase in disease resistance slightly more rapidly than the 8-year and 16-year cases. For the moderate mortality rate, little discriminates the population response under the three cycle periods (Fig. 8). The degree of development of disease resistance for the moderate-mortality case, without periodicity, is nearly as great as that observed for the high-mortality case with the two shortest periodicities. 

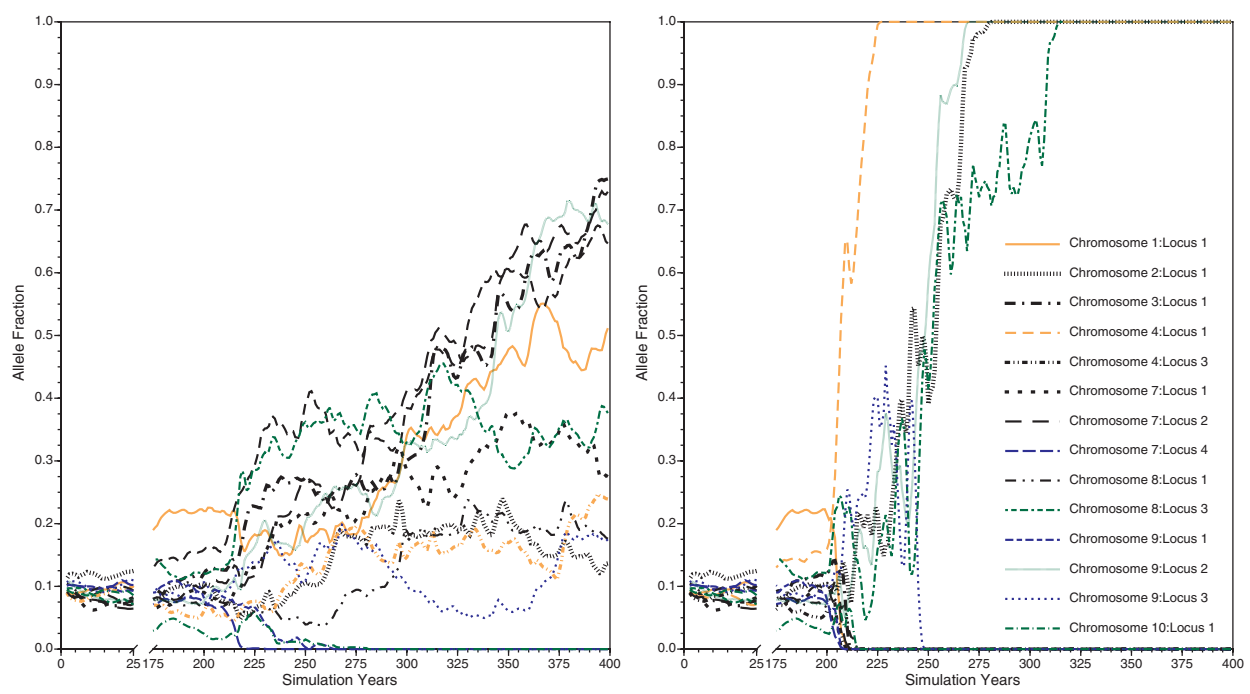

Figure 9. Trajectories for the fourteen alleles conferring disease resistance for the high-mortality Delaware Bay case (Table 2) with lower abundance and either a 16-year cycle or no-cyclicity. Dermo disease was not present in the first 200 years; during this time these alleles drifted as neutral alleles. Selection for disease resistance began in year 201. Color scheme as in Figure 4.

Lower abundance modifies this outcome (Fig. 8). First, the differentials between outcomes for the two mortality rates and three cycle periods are comparatively muted; disease resistance builds up somewhat more slowly in all cases. Second, the adult fitness for the population exposed to high-mortality without cyclic behavior asymptotes near Year 270. This aberration originates from the loss of alleles conferring disease resistance during the initial epizootic while they are still rare in the population; this allele loss later limits the population response. Cyclicity limits this allele loss (compare for example Figs. 4 and 9).

Note that asymptotic behavior in which the maximal level of adult fitness falls below 1 in subsequent simulations also is indicative of allele loss through drift. Nearly all such cases of allele loss occur shortly after the onset of disease and at the higher mortality rate (e.g., Figs. 8 and 10, no cyclicity, high mortality, low abundance).

\section{c. Modulation by population dynamics - growth rate and fecundity}

Growth rate may influence the potential of Dermo disease in controlling the oyster's population dynamics (Powell et al., 1996). We compared three sites, Delaware Bay, Chesapeake Bay, and the Gulf of Mexico. Differential growth rates (Fig. 1) did not materially influence the degree of development of disease resistance at any cycle period (Figs. 8-Low Abundance and Fig. 10). Variation in recruitment can also influence the development of dermo epizootics (Powell et al., 1996). Simulations in which egg production was varied 

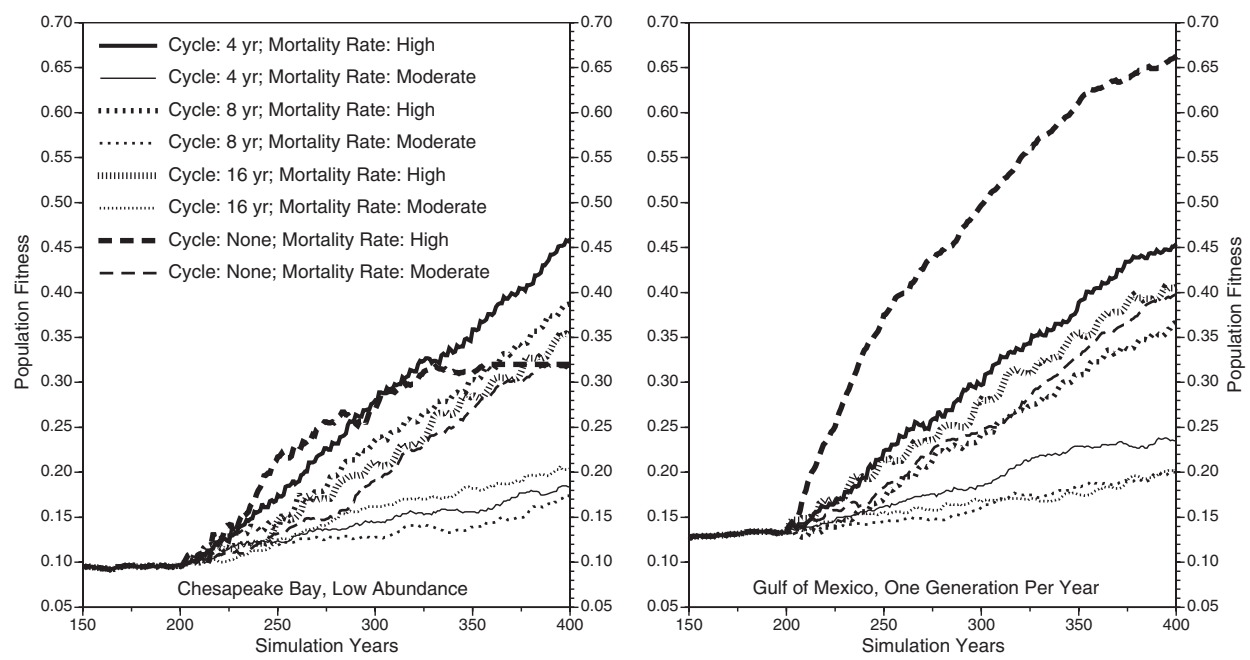

Figure 10. Population fitness for the Chesapeake Bay and Gulf of Mexico cases otherwise equivalent to Figure 8, Delaware Bay-Low Abundance case, for two levels of disease intensity and commensurate population mortality, three cycle periods, and the absence of periodicity (Table 2). The naïve, unexposed case is shown for Years 150-200. The two levels of disease, and the onset of cyclic mortality when specified, began in Year 201. Fitness ranges from 0 to 1 . Note that the y-axis reaches only 0.7 .

stochastically by as much as a factor of two between females of equivalent size produced trends in the development of disease resistance somewhat less rapid than the former three cases (Figs. 8-Low Abundance and Fig. 10) at the higher mortality rate, but overall the influence was relatively minor (Fig. 11). Varying the fraction of the population parenting the next generation produced approximately the same results (Fig. 11). Thus, variation in population dynamics did not much influence the outcome of the development of disease resistance when influenced by 4-year, 8-year, or 16-year cycles.

\section{d. Modulation by population dynamics - extreme conditions}

We increased the fraction of parents spawning by a factor of 10 . This is equivalent to a much higher effective population size. The development of disease resistance, if anything, was slowed by this condition (Fig. 12). We dramatically increased the size of the simulated population, by about a factor of 10. Results varied little from previous simulations (Fig. 12). Finally, we carried out a simulation using the higher growth rates characteristic of the Gulf of Mexico, but with two spawnings (and two generations) per year. Such conditions do occur at some Gulf locations. Two spawnings per year distinctly reduced the development of disease resistance in populations affected by 4-year, 8-year, and 16-year disease cycles (compare Figs. 10 and 12). 


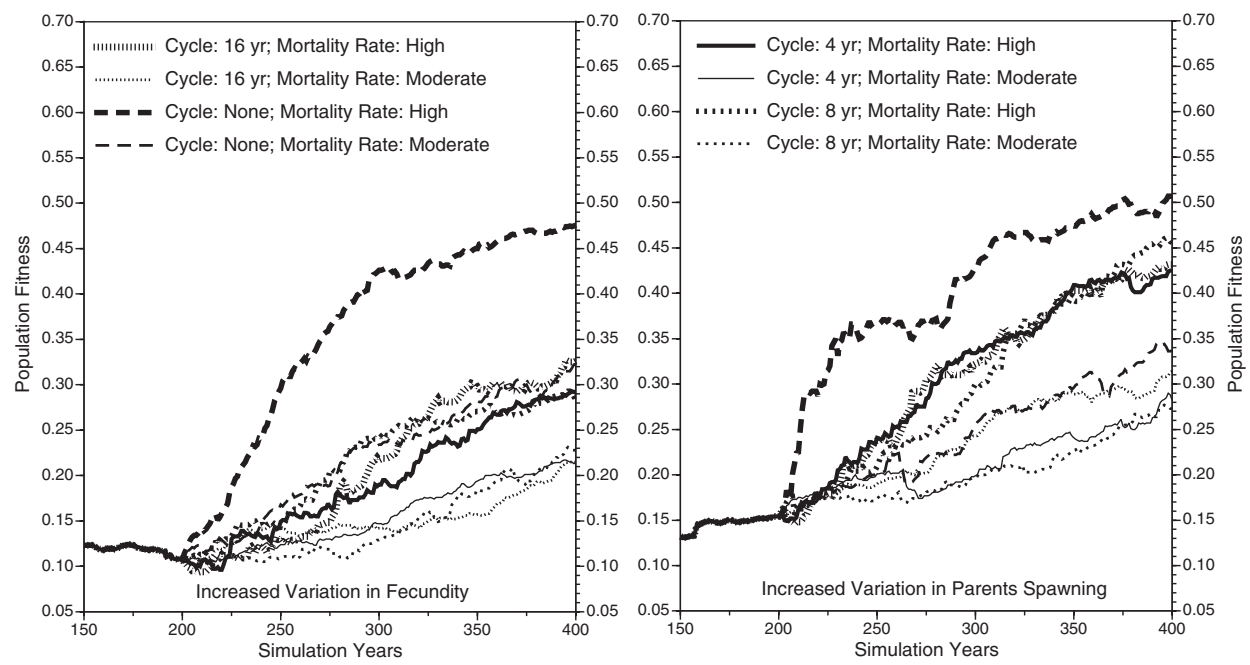

Figure 11. Population fitness for the Chesapeake Bay case for two levels of disease intensity and commensurate population mortality, three cycle periods, and the absence of periodicity, but with stochastic variation in egg production per female (Increased Variation in Fecundity) or stochastic variation in the fraction of parents spawning (Table 2). The comparative figure is in Figure 10. The naïve, unexposed case is shown for Years 150-200. The two levels of disease, and the onset of cyclic mortality when specified, began in Year 201. Fitness ranges from 0 to 1 . Note that the y-axis reaches only 0.7 .

\section{e. Variation in allele number}

Certain of the alleles conferring disease resistance (Table 1) may endow a greater increment in survival than others; however, insufficient data are available to weight their relative importance. Thus, one possibility is that only a few of the alleles provide most of the fitness response. Accordingly, we compared the cases for Delaware Bay (Fig. 8) and Chesapeake Bay (Fig. 10) with two cases for Chesapeake Bay in which fewer alleles conferred disease resistance. We selected from the fourteen loci with alleles conferring disease resistance two synthetic sets of loci, a set of seven and a set of two. All of the chosen loci exhibited dominance; the loci exhibiting underdominance were eschewed. Specifications are provided in Table 2. Note that the outcome of the two-loci case is strongly dependent upon locus choice. Choosing loci showing underdominance, for example, would very likely produce strongly divergent results.

Reducing the number of loci from fourteen to seven did not materially change the outcome for any cycle period, as measured by the degree of acquisition of disease resistance over 200 years, although it enhanced the response for the population continuously exposed to the disease (Fig. 13). Reducing the number of loci from fourteen to two dramatically modified the outcome (Fig. 13). In this case, full disease resistance was established in many 


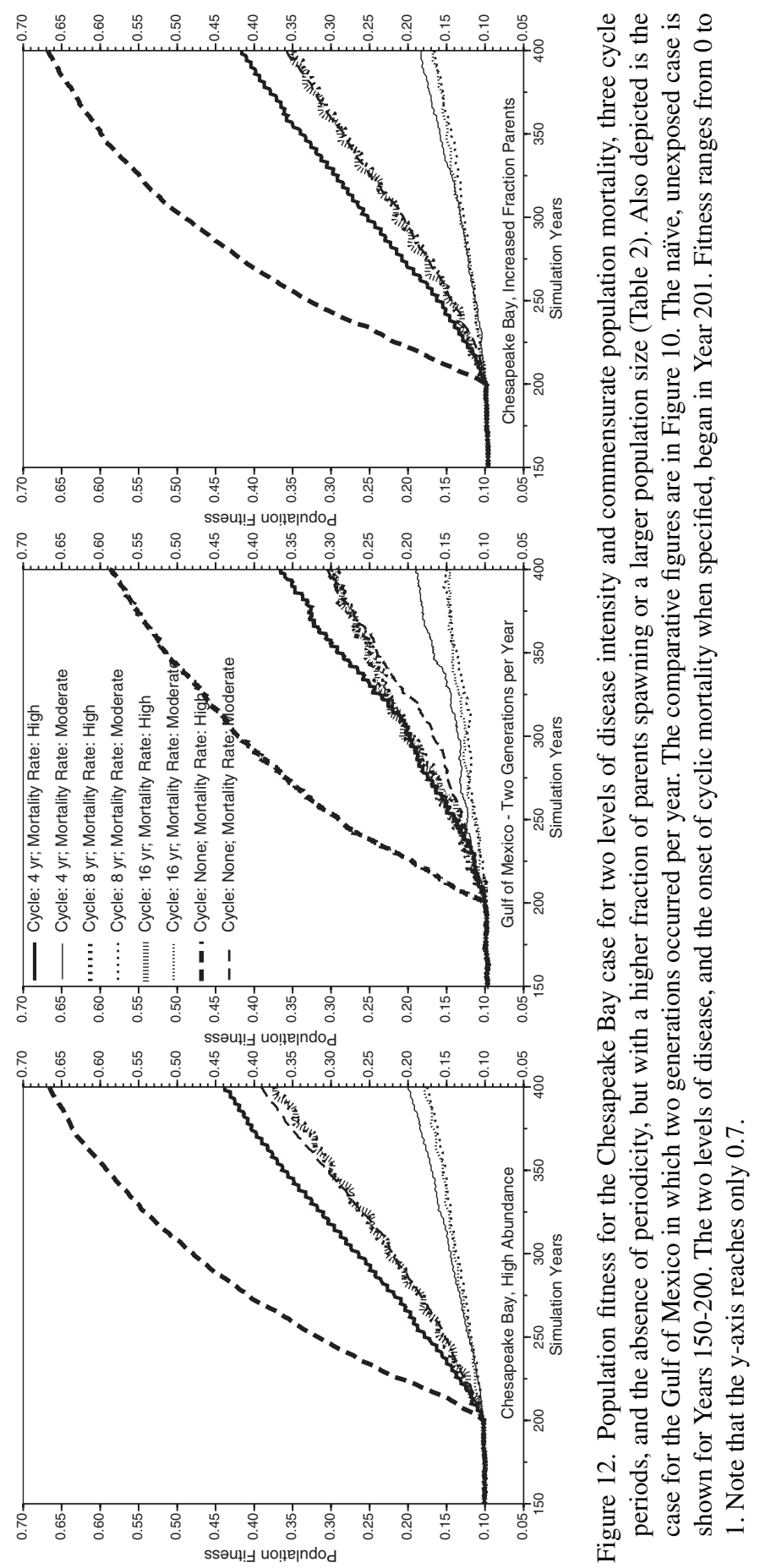



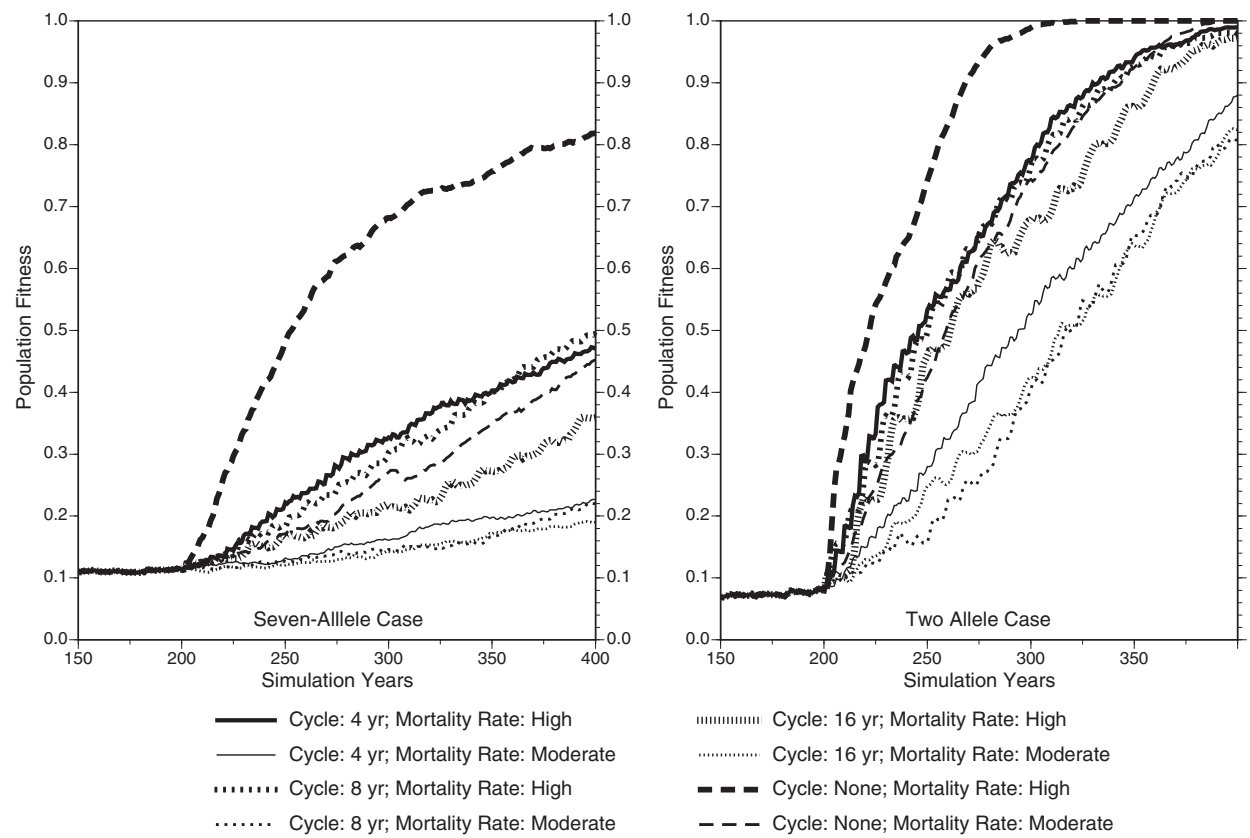

Figure 13. Population fitness for a Chesapeake Bay case with seven and with two, rather than fourteen, loci with alleles conferring disease resistance, for two levels of disease intensity and commensurate population mortality, three cycle periods, and the absence of periodicity (Table 2). The comparative cases are in Figures 8 and 10. The naïve, unexposed case is shown for Years 150-200. The two levels of disease, and the onset of cyclic mortality when specified, began in Year 201. Fitness ranges from 0 to 1 .

simulations within 200 simulation years and all cases resulted in population fitnesses of 0.8 or higher on the 0 -to-1 scale, regardless of cycle period.

\section{Discussion}

\section{a. Perspective}

Cyclicity in climate is paradigmatic in oceanography. A plethora of investigations into the dynamics of marine organisms relate climate cycles to a host of outcomes (e.g., Fromentin and Planque, 1996; Tunberg and Nelson, 1998; Harvell et al., 2002; Zuur and Pierce, 2004). Oysters are no exception (Owen, 1953; Schoener and Tufts, 1987; Ebbesmeyer and Strickland, 1995; Powell et al., 2009a; Soniat et al., 2006, 2009). The influence of climate cycles on disease, though documented (e.g., Kim and Powell, 1998; Kim et al., 1999; Hayes et al., 2001; Jaenike, 2002; Harvell et al., 2002), are less universally described because the dynamics of transmission are influenced by many processes of varying timing and origination and the development of epizootics often depends upon contact between infected 
and susceptible hosts that may subsume a complexity of behavior, thus limiting expression of a climatic influence. For some marine diseases, transmission rates are sufficiently rapid that the influence of disease is measured more in terms of infection intensity than prevalence. Dermo is one of these diseases (Mackin, 1962; Hofmann et al., 1995; Audemard et al., 2006; McCollough et al., 2007). In these cases, typically, climate has a more direct and immediate influence on the development of disease epizootics because most hosts are infected and, so, the rate of proliferation of the pathogen is paramount; and this rate is often environmentally controlled. Dermo is one of these diseases (Soniat et al., 2006, 2009).

Crassostrea virginica covers an extended latitudinal range much beyond the range of any of its diseases and parasites (Kim and Powell, 2006, 2009), and well beyond the range where any specific climate cycle holds principal sway. Thus, ENSO is a prognosticator of dermo disease in the Gulf of Mexico; the NAO is much more influential north of Cape Hatteras (Soniat et al., 2009). As a consequence, we investigated a number of cycle periods and also a number of von-Bertalanffy-based population dynamics, covering typical conditions from the Mid-Atlantic Bight to the Gulf of Mexico.

Our goal was to inform on a conundrum. Dermo has been a regulating force in oyster population dynamics in the Gulf of Mexico since at least the late 1940s (Dawson, 1955; Ray and Chandler, 1955; Mackin, 1953, 1962), in Chesapeake Bay since at least the early 1950s (Andrews, 1954, 1996; Hewatt and Andrews, 1954), and in Delaware Bay since 1990 (Ford, 1996). These time scales span minimally a score and maximally more than 100 generations of oysters, yet observations, meager though they are, have documented little development of disease resistance. In the Gulf of Mexico, mortality rates on the order of 50\% per year are commonplace (e.g., Mackin et al., 1950; Mackin, 1959; Soniat and Brody, 1988). Farther north, in Delaware Bay, the mortality rate is lower; however, even here, dermo disease at least doubles the natural mortality rate of the market-size animals in epizootic years (Powell et al., 2008, 2009a). Mortality rates of this order might be expected to result in rapid development of disease resistance in the naïve population (e.g., Duffy and Sivars-Becker, 2007; Zbinden et al., 2008; Duffy et al., 2009). Indeed oysters responded as anticipated to MSX disease (Haskin and Ford, 1979; Ford, 1988; Ragone Calvo et al., 2003), yet this expectation remains unrealized for dermo disease.

A number of possible resolutions to this enigma may be postulated. (1) Perkinsus marinus can reside intracellularly in hemocytes (Mackin, 1962; Goedken et al., 2005) as well as extracellularly throughout the tissues and the cell coat may contain antigens unrecognized by the oyster's immune system (see Choi et al. 1991; Dungan and Roberson, 1993; Montes et al., 2005). This crypticness may limit the oyster's genetic response to the disease. The density dependency of P. marinus doubling times at higher infection levels may be an abetting agent. (Saunders et al., 1993). (2) Development of resistance to dermo disease may be rapidly countered by changing virulence. Different strains of $P$. marinus have been observed (Bushek and Allen, 1996; Gaffney and Bushek, 1996; Reece et al., 2001; Panko et al., 2008) and one suspects that these may be associated with a range of virulence (Brown et al., 2005a,b; Earnhart et al., 2004), although data remain limited on this 
topic. The competition between the development of host resistance and the progression of parasite virulence is a well-documented component of host-parasite evolutionary models (e.g., Boots et al., 2004; Schneider and Ayers, 2008; Duffy and Forde, 2009). Whether such an interplay is at work in oyster populations remains unknown. (3) Perkinsus marinus dominantly kills mature animals, typically after at least one spawning cycle. Impact on oyster reproduction does not occur until infection intensity nears lethal levels (Choi et al., 1989; Paynter, 1996; Dittman et al., 2001). Thus, spawning is little influenced by disease intensification and many animals may spawn a number of times before death.

Powell et al. (2011a) examined the vexing mismatch of time span of exposure in comparison to increment in disease resistance from the aspect of basic population dynamics and the genetic response to selection. Their aspiration was to determine whether aspects of the host's genetics or population dynamics limit the response to the disease despite the apparent opportunity afforded the host by alleles conferring disease resistance. They concluded that a significant population response to dermo disease challenge might be expected to take place, even at its most rapid rate, on decadal to vicennial time scales. At moderately increased mortality, a half-century time scale is more likely. This languidness of response is rooted in the confluence of two determinants. First, the large number of alleles conferring some degree of disease resistance perversely slows the overall functional response. Second, the relative rates of $P$. marinus proliferation and oyster growth assure that most females will reproduce at least once before death, often more than once, and pre-mortality morbidity is limited to animals nearing death; thus, morbidity is an inconsequential contributing agent. Accordingly, one anticipates selection to be relatively insensitive to exposure until death occurs. Together, the result is a perturbingly slow development of disease resistance.

Dermo disease is characterized by cyclic behavior, as pathogen proliferation, and consequently mortality, is affected by temperature and salinity. Temperature generates the yearly progression and regression of infection intensity (Andrews, 1988; Burreson and Ragone Calvo, 1996; Ray, 1996). Longer-term changes in temperature and precipitation generate multi-year signals in infection intensity recognized as cyclic epizootics (Soniat et al., 2006, 2009). ENSO and NAO are principal instigants. The cyclicity introduces periodicity in selection, in that selection is only strong at cycle apogee when mortality rate is maximal. Possibly, the congruence of the cycle period with the generation time is important. Cycle periods less than the generation time might permit some sensitive individuals to escape mortality, thus lessoning selection. Cycle periods longer than the generation time might permit multiple generations to be exposed during one epizootic and also multiple exposures for a single cohort. However, cyclicity in the disease process may also influence generation time by enforcing coherency between cycle period and average life span (Powell and Cummins, 1985). Of possibly more influence is the simple fact that cycles relieve the population of an overarching source of mortality for a period of time near cycle nadir, and this lowers the time-integrated mortality rate. The mortality rate is the preponderant agent of selection imposed by the disease. Thus, cyclicity, simply by varying disease pressure, should retard the development of disease resistance. 


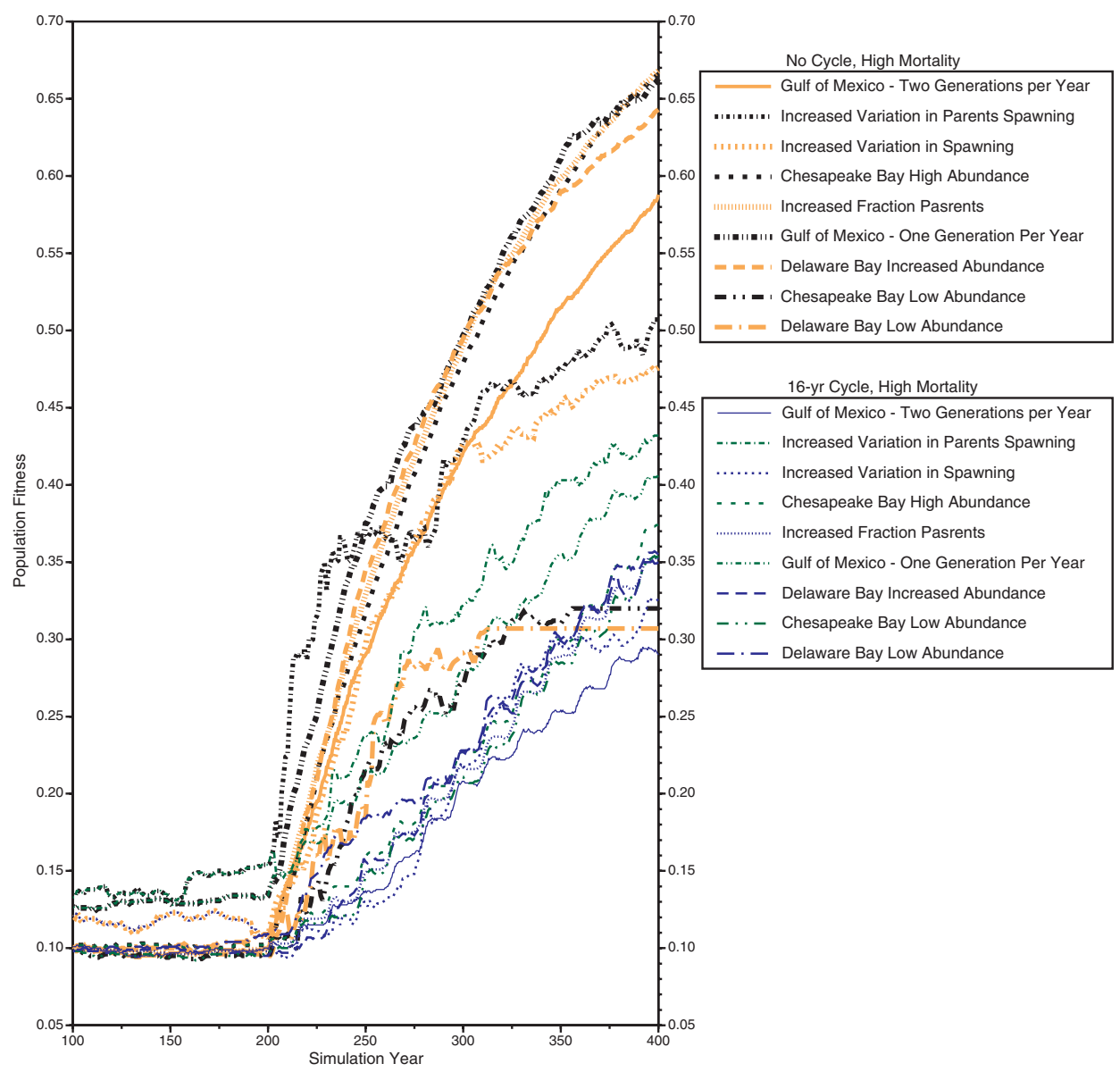

Figure 14. Trajectories for population fitness summarized for the simulations described in Figures 8 and 10-12 with and without a 16-year cycle in disease mortality imposed and with the highmortality rate. Note that the y-axis rises to 0.70 in comparison to Figure 15 wherein the y-axis reaches only 0.45 .

\section{b. The influence of disease cycles}

Cycles profoundly influence the development of disease resistance, converting a depressingly slow process into a one of ponderous pace. Figure 14 compares a series of simulated populations in which a high mortality rate was imposed with and without a 16-year cycle. The simulation without the 16-year cycle yielding the slowest rate of development of disease resistance is for a population that develops disease resistance distinctly more rapidly than the population with the most intense response under the 16-year cycle, discounting two simulations in which many alleles were lost by drift as discussed later. The case that records 
the greatest level of development of disease resistance with cyclic disease is the case for the Gulf of Mexico (Fig. 10). The rapid rate of growth fosters increased fecundity of animals at young age. By comparison, the case with the most languid development of disease resistance, in which allele loss through drift was insignificant, is the case in which increased stochasticity in egg production resulted in an enhanced likelihood that pairs of susceptible individuals would excel in the sweepstakes competition ${ }^{8}$ (see Hedgecock et al., 2007; Hofmann et al., 2009). This tendency increased the retention of susceptible individuals in the population, thereby reducing the rate of development of disease resistance.

The cases depicted in Figure 14 are one extreme set of simulations, representing the cycle of longest period and the highest mortality rate. A potentially diametric case depicted in Figure 15 is a set of simulations for populations exposed to a 4-year cycle under moderate mortality compared to populations without the cycle. The results are altogether consistent with the previous set (Fig. 14), albeit the deviation of the two groups, populations exposed to cyclic or continuously increased mortality, is muted by the limited development of disease resistance possible under this mortality rate, even if the population is continuously exposed to the disease (the no-cycle cases).

Focusing on the case for Delaware Bay, the 16-year high-mortality case results in a population achieving a fitness level of 0.355 on a 0 -to- 1 scale after 200 years of exposure to disease. The equivalent outcome if the disease was continuously present over the 200 years, without cyclicity, is 0.645 , a fitness level not quite twice as high (Fig. 14). In the other example, a population exposed to disease with a 4-year cycle and moderate mortality results in a population fitness value after 200 years of 0.182 . When the disease is continuously present, the population fitness value achieved after 200 years is 0.346 , a value again nearly twice as high (Fig. 15). The differential is consistent with the reduction in exposure to disease mortality anticipated from the cycle. The differential being near a factor of two is, however, somewhat unique to the parameter values used for these simulations. Other parameterizations depicted in Figure 14 yield differentials ranging from 0.86 , limited divergence, to 0.53 , nearly a factor of two divergent. Thus, the cycle routinely results in a retarded rate of development of disease resistance in these simulated populations of somewhere between half and $80 \%$ of the non-cycle rate.

Consequently, the simulations as a whole suggest that cyclic disease reduces the incremental rate of development of disease resistance and that this reduction often is of appreciable degree. Much of this influence likely is due to the reduction in the time-integrated population mortality rate, which will approximate half the apogean rate. This relaxation of the mortality rate enhances survival of animals with a lower complement of alleles conferring disease resistance for part of the cycle. Moreover, this relaxation permits rare alleles, such as alleles conferring disease resistance in the naïve population, to drift and given the sweepstakes assumption of population dynamics (e.g., Hedgecock et al., 2007), most often,

8. Sweepstakes reproductive success "occurs when a small fraction of adults contributes the vast majority of new recruits while the remaining adults contribute average numbers of, or no, offspring" (Hofmann et al., 2009). 


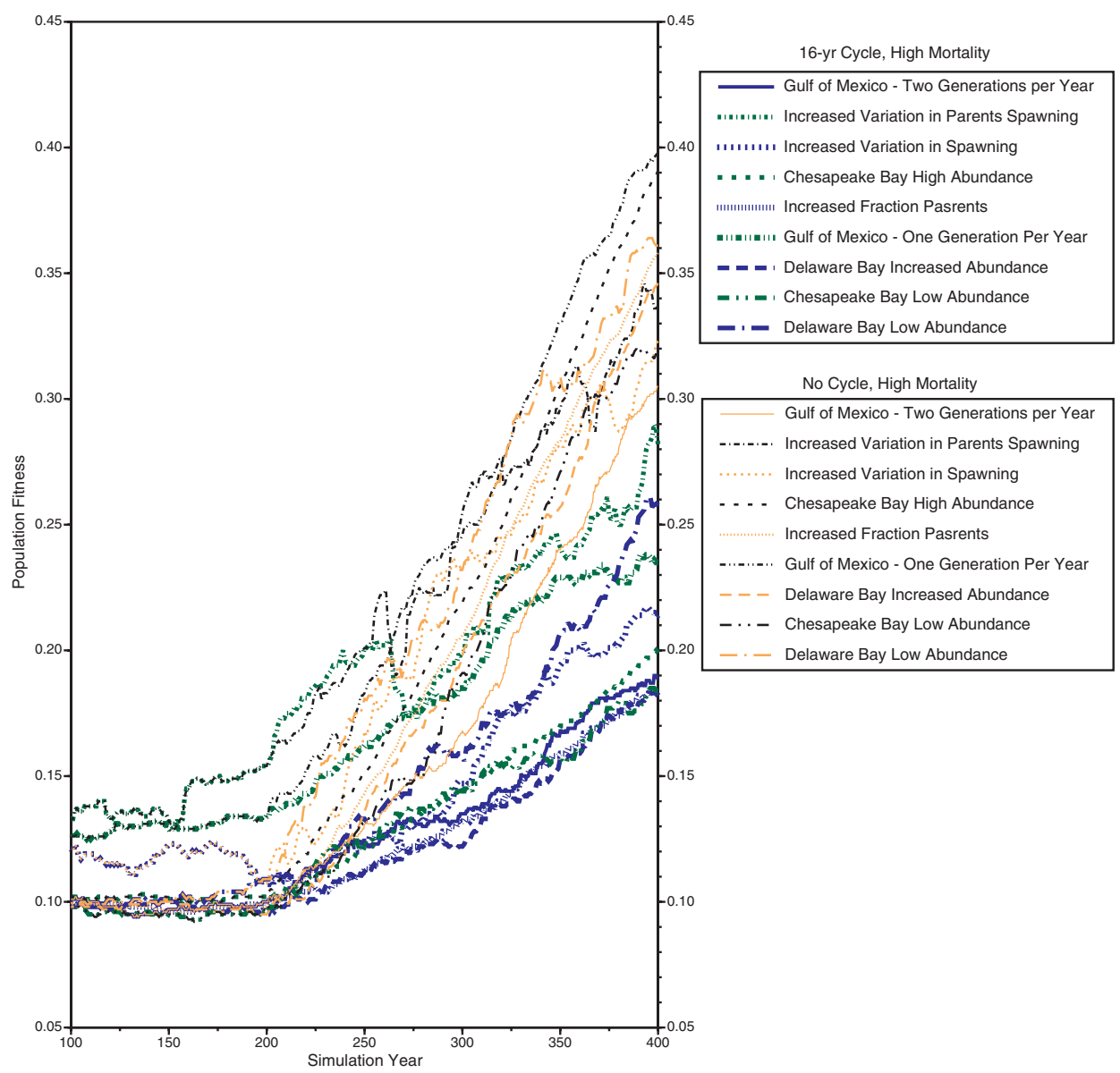

Figure 15. Trajectories for population fitness summarized for the simulations described in Figures 8 and 10-12 with and without a 4-year cycle in disease mortality imposed and with the moderate mortality rate. Note that the y-axis rises only to 0.45 in comparison to Figure 14 wherein the y-axis reaches 0.70 .

that drift is towards lower frequencies because fewer animals carrying these alleles predestines a lower probability of their successful dissemination during sweepstakes reproduction at cycle nadir.

\section{c. The influence of cycle period}

An expectation arises that the length of the cycle period may influence the outcome. In the few years following onset of the disease, of course, it must, as the naïve population is differentially exposed over the first several epizootics depending upon cycle period relative 


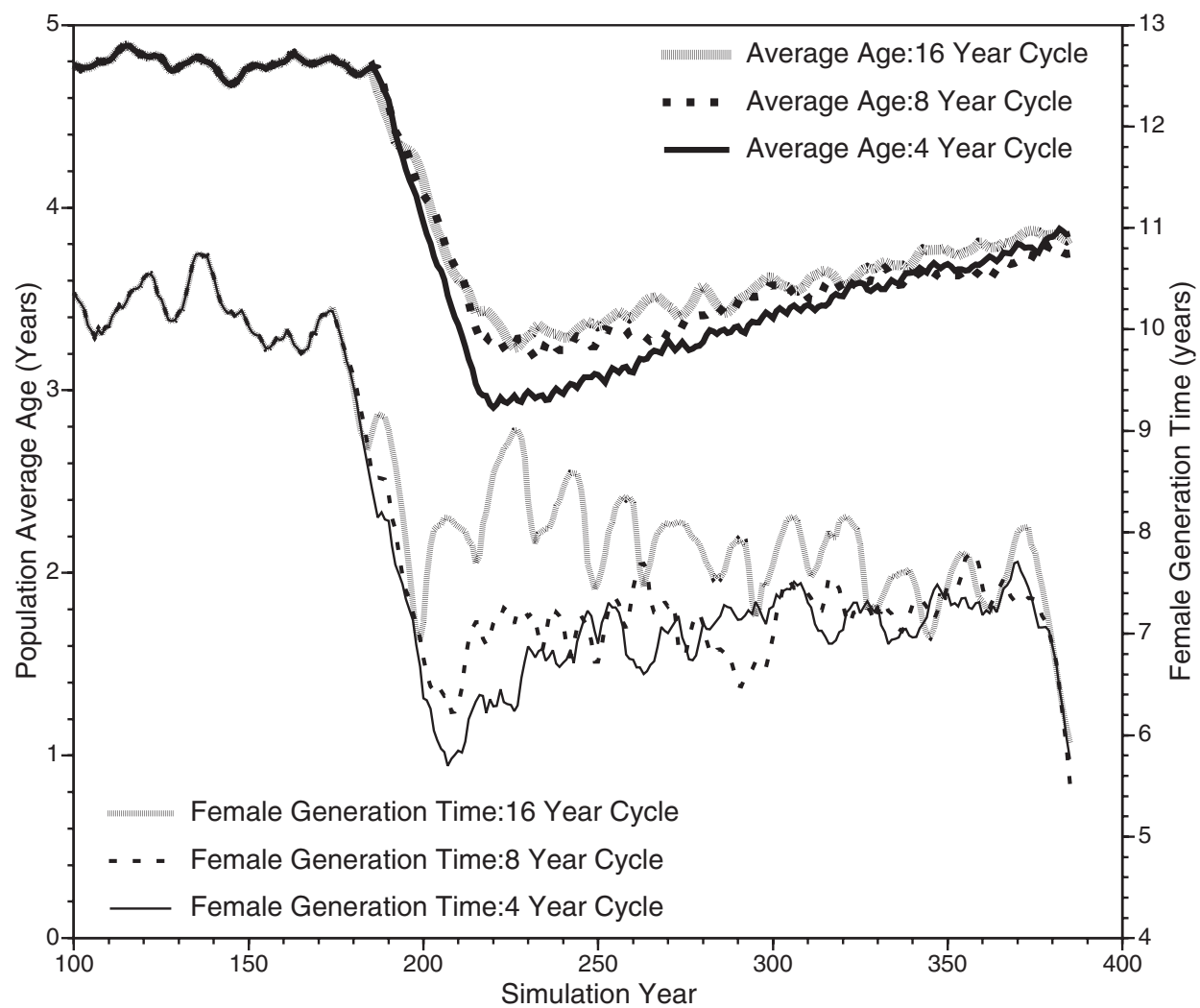

Figure 16. Comparison of average population age and female generation time for three cases parameterized for Delaware Bay (after Figure 8) with a high-mortality rate imposed upon onset of the disease in Year 201, but with different cycle periods of 4 years, 8 years, and 16 years.

to continuous exposure. However, over a longer period of time, the differential anticipated from variations in cycle period is much muted. Dermo increases population mortality rate. This generates two interrelated modifications to the population dynamics. The average age of the population declines and the generation time of females is reduced. The generation time of males is less influenced because protandry converts males to females and so many males become, in a sense, senescent at early age.

The cases for Delaware Bay are compared in Figure 16. Variation in cycle period has limited influence on population average age. The population exposed to a 4-year cycle evinces a transient reduction in average age shortly after onset of disease, but that differential degrades persistently over time (Fig. 16). A larger, yet still transitory, differential occurs for female generation time. In this case, generation time averages considerably longer with the 16-year cycle following the onset of disease. The slow growth rates and inherently 
long time to maturity exaggerate this difference. Thus, over an extended time period, this simulation suggests that differences in cycle period, over a range of biologically-relevant climate-cycle periods influencing oyster population dynamics, inconsequentially influence generation time and trivially influence population average age.

Review of the diversity of cases parameterized with varying population dynamics shown in Figures 8 and 10-13 discloses that population fitness tends to increase more rapidly in populations exposed to a 4-year cycle than a 16-year cycle, whenever a differential between the two exists, even though, for both cycle periods, the integrated mortality rate is half the apogean rate. Such a differential is not present in every case, but when it is, very likely the differing outcomes originate in the transiently higher generation time following onset of disease in the simulations with a 16-year cycle (Fig. 16). This extended generation time initially retains for a longer period alleles abetting disease susceptibility by permitting animals carrying them to reproduce more than once during the cycle's nadiral phase.

One might assume that drift is inconsequential in most oyster populations, even with the low effective population sizes, because total abundance is high. Several simulations conducted with a reduced carrying capacity to keep abundance low (e.g., Figs. 8-Delaware Bay Low Abundance and 10-Chesapeake Bay Low Abundance) provide cases where drift was consequential. When alleles are lost by drift, that loss typically occurs early after the onset of disease when mortality rates climb and population abundance falls. Alleles conferring disease resistance, being rare, are often lost during this time, because each contributes in only a small way to adult fitness and, hence, increased survival. Cyclicity substantively reduces the probability of allele loss (Fig. 9). Much of this counteraction emanates from the lower time-integrated mortality rate as mortality rate is near pre-disease levels at cycle nadir. Regardless, however, onset of dermo, which can result in population mortality rates fully three times pre-disease rates or more during at least the initial epizootics, might promote wholesale loss of alleles, were it not for a combination of auspicious population size and cyclicity limiting the duration of the epizootic to a time span on the order of the pre-disease generation time or less. This is true for both the ENSO and NAO instigants.

\section{d. Potential modulators of the process}

Population abundance, effective population size, variability in fecundity at size, variability in the number of individuals successfully producing recruits, and differential growth may influence the rate of development of resistance to dermo disease. Some conditions simulated, such as differential growth, are based on known variability in oyster population dynamics. Others likely exceeded the typical ambit, although confirmatory data are inadequate. Regardless, the range of responses in the rate of development of disease resistance was limited for this suite of simulations conducted under the constraint of a moderate increase in mortality rate (Fig. 15). Population fitness varied from just under 0.2 to nearly 0.3. Thus, the response to the disease did not vary substantially over a broad spectrum of oyster population dynamics. The situation differed only modestly with a higher mortality 


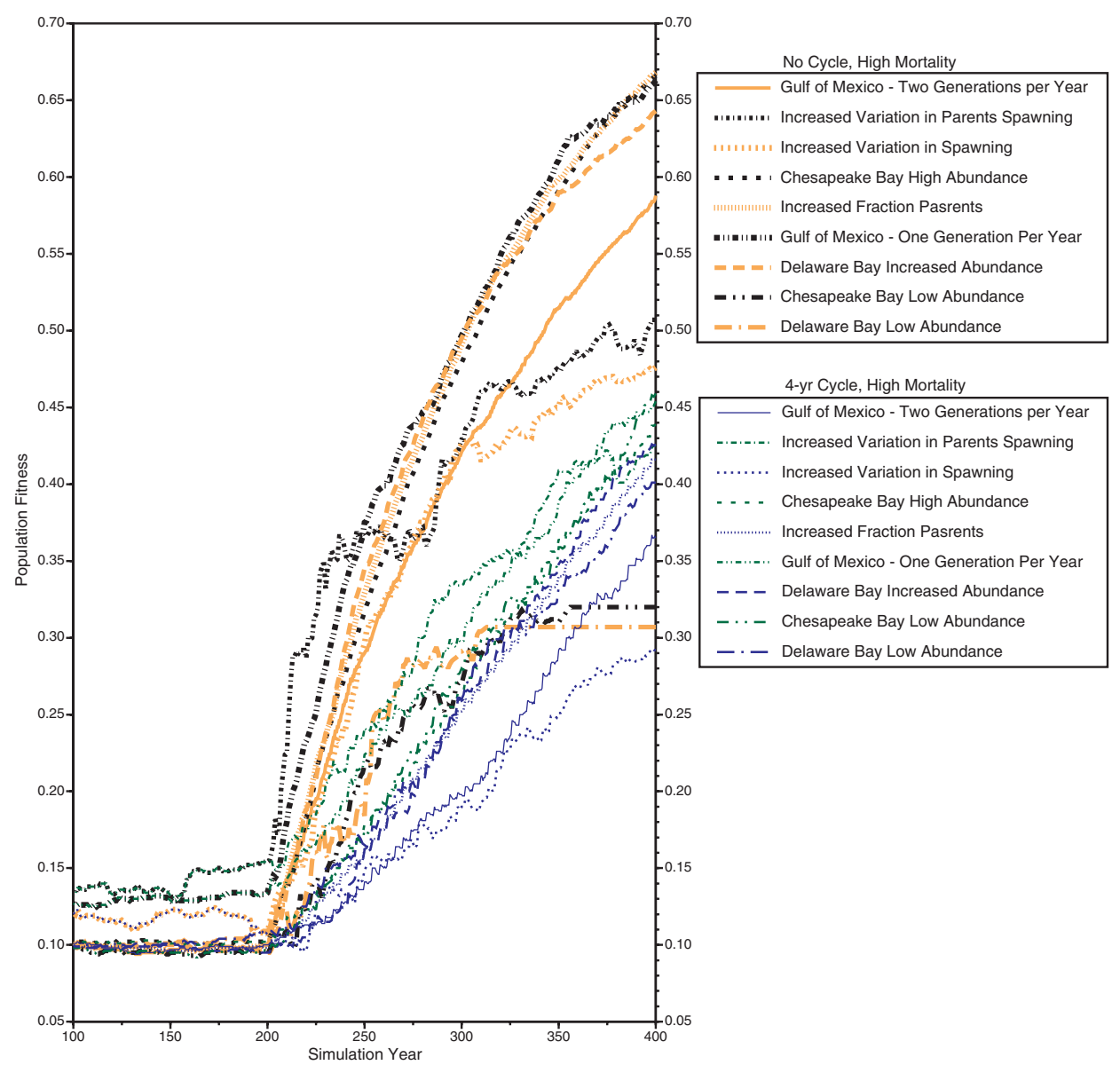

Figure 17. Trajectories for population fitness summarized for the simulations described in Figures 8 and 10-12 with and without a 4-year cycle in disease mortality imposed and with the high-mortality rate.

rate (Fig. 17). Simulations with a 4-year (or 16-year) cycle varied in population fitness from just under 0.3 to 0.45 (Figs. 14 and 17), a narrow range in outcomes little dependent upon cycle period. Thus, overall, details of the population dynamics little influence the outcome. The mortality increment due to disease was the overriding feature, modulated to a much smaller degree by the cycle period.

\section{e. The curious case of the Gulf of Mexico}

The exposure period to dermo is considerably longer in Gulf-coast oysters than for oysters in northeastern estuaries. Exposure to dermo is recorded at least since the late 1940s (e.g., 
Mackin et al., 1950; Mackin, 1953, 1959) and arguably dermo has been present for a much greater period of time (Ray, 1996). On the other hand, at least one circa-1900 survey documents oyster populations with density and size-frequency characteristics that suggest a limited influence of the disease (Moore, 1907) in an area now heavily impacted (Craig et al., 1989; Wilson et al., 1990). Irrespective of the long-term history, even the most conservative estimate is an exposure period exceeding 60 years. Although not well documented, the mortality levels of the 1950s would seem to be apropos for the modern day. Certainly, dermo infection intensities remain high throughout much of the Gulf of Mexico (Craig et al., 1989; Wilson et al., 1990; Kim et al., 2001).

Consider, therefore, the possibility that $>60$ years of exposure has not resulted in a substantive improvement in disease resistance. Why? Note in Figs. 14-15 and 17 that the case parameterized for the Gulf of Mexico with one generation per year typically results in population fitnesses after 200 years nearly as high or higher than any of the remainder, in opposition to expectation from, albeit anecdotal, observation. Note however, in the same figures, that the case parameterized for the Gulf of Mexico with two generations per year typically results in population fitnesses after 200 years nearly as low or lower than any of the remainder. The Gulf of Mexico is strongly influenced by ENSO (Douglas and Englehart, 1981; Tolan, 2007; Soniat et al., 2006), that generates 4-year cyclicity in salinity, and consequently dermo infection intensity (Soniat et al., 2006, 2009). A 4-year cycle coupled with multiple generations per year severely impedes the rate of development of disease resistance in simulated populations. Although two generations per year is not necessarily fully realized in all locations, multiple spawnings per year are certainly the norm (Hopkins, 1954; Hayes and Menzel, 1981; Hofmann et al., 1994) resulting in a portion of the yearly recruits entering their first spawning season with limited exposure to the disease. This reduces the overall mortality rate, enhancing lifetime egg production, and permits common alleles, those enhancing disease susceptibility, to be retained in the population more readily by bypassing some portion of the lifetime selection pressure.

Whereas the inherent limitation in the response of the oyster to dermo disease may ultimately be explained by a variety of immune-system-related idiosyncrasies determining the relationship between the parasite and its host, or to the ability of Perkinsus marinus to evolve virulence factors in parallel to adaptation by the oyster host, the simulations supporting this study suggest that basic characteristics of oyster population dynamics in the Gulf of Mexico coupled with the imprint of the ENSO cycle would be sufficient to reduce the rate of development of disease resistance to a level that might not be detected over a 60 -year period without a robust and detailed time series. Such a data resource does not exist.

\section{Conclusions; Expectations for the future: dermo and oyster population dynamics}

Unquestionably, dermo exerts a controlling influence on oyster population dynamics wherever environmental conditions permit epizootics to occur. Increments in mortality 
easily are a factor of two to three above the nonepizootic rate. Such rates strain the oyster population's ability to respond because neither recruitment nor growth rate have an equivalent ambit. As a consequence, abundance declines and can decline precipitously. Unquestionably, oysters can develop disease resistance to some protozoal diseases rapidly (e.g., Andrews, 1968; Farley, 1975; Ford and Haskin, 1982; see also Burreson, 1991; Burreson et al., 2000; Burreson and Ford, 2004), as well as to prokaryotic challenge (Ford and Tripp, 1996; Barber et al., 1998; Oliver et al., 2003; Gómez-León et al., 2008). Dermo is a relatively unique parasite in both its suspiciously cryptic relationship with the oyster's immune system and its overt persistence as a source of mortality. Moreover, more than many other parasites and diseases (Kim and Powell, 2006, 2007; Kim et al., 2009), dermo is highly sensitive to climate cycles that influence temperature and salinity; consequently, epizootics are frequently cyclic phenomena.

Perkinsus is a wide ranging genus infecting a variety of clams and oysters (e.g., McLaughlin et al., 2000; Ngo and Choi, 2004; Leethochavalit et al., 2004; Bushek et al., 2008); whether the inferences derived herein for dermo disease can be applied more generally is unknown. Nevertheless, the simulations presented here bolster the conclusion that resistance to dermo disease cannot develop save slowly in oyster populations (Powell et al., 2011a). A large number of loci contributing alleles conferring disease resistance, the cyclic nature of the exposure relieving the population in predictable time units from selection pressure, and the tendency for conditions that might improve development of disease resistance such as rapid growth to be counterbalanced by multiple yearly spawnings, hamper the rapid development of disease resistance. Half-century to century time scales are implied by our simulations, even if the immune system is not compromised by crypticness or adaptively enhanced virulence of the parasite. Over a typical observational period of a decade or so, one should not expect to see an easily measurable increment in disease resistance.

Documented epizootics imply an additional impediment. Epizootic mortality rates at cycle apogee, twice that observed at cycle nadir or prior to the onset of disease, are consequential from the standpoint of population sustainability, judging from fisheries-related databases (e.g., Powell et al., 2008) that suggest overfishing at mortality rates of $20 \%$ per year or more. This same increment in mortality rate would seem insufficient to generate anything but modest rates of development of disease resistance, however. A tripling of mortality rate yields a more rapid development of disease resistance. However, epizootics of this scale are also rarer. Moreover, the more rapid increment in disease resistance anticipated from the more extreme selection events relatively rapidly reduces the increment in mortality rate to that factor of two that is still overwhelmingly consequential for oyster population dynamics, but a limited promoter of selection. This mismatch between expectation inferred from the dire influence of a doubled mortality rate on population dynamics and the capacity of selection inherent to the oyster's genetic structure leads to the surmise that disease resistance that has not increased measurably to date may be anticipated to develop with elephantine slowness in the future. In fact, the periodicity of dermo epizootics may doom 
oyster populations to an extended period of low abundance, during which disease resistance slowly improves; bit by bit limiting the depredations of the disease.

Acknowledgments. Funding was provided by the NSF Biocomplexity in the Environment program grant \#OCE-0412696 and the NSF Ecology of Infectious Diseases program grant \#OCE-0622672. We appreciate this support.

\section{REFERENCES}

Addison, C. 2006. Oyster recruitment and early growth patterns in the Barataria Estuary. Masters Thesis, Nicholls State University, Thibodaux, Louisiana. 119 pp.

Andrews, J. D. 1954. Notes on fungus parasites of bivalve mollusks in Chesapeake Bay. Proc. Natl. Shellfish. Assoc., 45, 157-163.

— 1968. Oyster mortality studies in Virginia VII. Review of epizootiology and origin of Minchinia nelsoni. Proc. Natl. Shellfish. Assoc., 58, 23-36.

1988. Epizootiology of the disease caused by the oyster pathogen Perkinsus marinus and its effects on the oyster industry. Am. Fish. Soc. Spec. Publ., 18, 47-63.

- 1996. History of Perkinsus marinus, a pathogen of oysters in Chesapeake Bay 1950-1984. J. Shellfish Res., 15, 13-16.

Andrews, J. D. and W. G. Hewatt. 1957. Oyster mortality studies in Virginia. II. The fungus disease caused by Dermocystidium marinum in oysters of Chesapeake Bay. Ecol. Monogr., 27, 1-25.

Arizpa, C. O. 1996. Secondary production, growth and survival of the Pacific oysters Crassostrea virginica (Thunberg) in tropical waters, Bahia de la Paz, Mexico. J. Shellfish Res., 15, 601-607.

Attrill, M. J. and M. Power. 2002. Climatic influence on a marine fish assemblage. Nature (Lond.), 417, 275-278.

Audemard, C., L. M. Ragone Calvo, K. T. Paynter, K. S. Reece and E. M. Burreson. 2006. Realtime PCR investigation of parasite ecology: in situ determination of oyster parasite Perkinsus marinus transmission dynamics in lower Chesapeake Bay. Parasitology, 132, 827-842.

Barber, B. J., C. V. Davis and M. A. Crosby. 1998. Cultured oysters, Crassostrea virginica, genetically selected for fast growth in the Damariscotta River, Maine, are resistant to mortality caused by Juvenile Oyster Disease (JOD). J. Shellfish Res., 17, 1171-1175.

Barber, B. J., S. E. Ford and R. N. Wargo. 1991. Genetic variation in the timing of gonadal maturation and spawning of the Eastern oyster, Crassostrea virginica (Gmelin). Biol. Bull. (Woods Hole), 181, 216-224.

Bojariu, R. and L. Gimeno. 2003. Predictability and numerical modelling of the North Atlantic Oscillation. Earth-Sci. Rev., 63, 145-168.

Boots, M., P. J. Hudson and A. Sasaki. 2004. Large shifts in pathogen virulence relate to host population structure. Science (Wash. D.C.), 303, 842-844.

Brown, B. L., A. J. Butt, D. Meritt and K. T. Paynter. 2005a. Evaluation of resistance to Dermo in eastern oyster strains tested in Chesapeake Bay. Aquacult. Res., 36, 1544-1554.

Brown, B. L., A. J. Butt, S. W. Shelton, D. Meritt and K. T. Paynter. 2005b. Resistance of Dermo in eastern oysters, Crassostrea virginica (Gmelin), of North Carolina but not Chesapeake Bay heritage. Aquacult. Res., 36, 1391-1399.

Burreson, E. M. 1991. Effects of Perkinsus marinus infection in the eastern oyster, Crassostrea virginica: I. Susceptibility of native and MSX-resistant stocks. J. Shellfish Res., 10, 417-423.

Burreson, E. M. and S. E. Ford. 2004. A review of recent information on the Haplosporidia, with special reference to Haplosporidium nelsoni (MSX disease). Aquat. Living Resour., 17, 499-517. 
Burreson, E. M. and L. M. Ragone Calvo. 1996. Epizootiology of Perkinsus marinus disease of oysters in Chesapeake Bay, with emphasis on data since 1985. J. Shellfish Res., 15, 17-34.

Burreson, E. M., N. A. Stokes and C. S. Friedman. 2000. Increased virulence in an introduced pathogen: Haplosporidium nelsoni (MSX) in the eastern oyster Crassostrea virginica. J. Aquat. Anim. Health, 12, 1-8.

Bushek, D. and S. K. Allen Jr. 1996. Host-parasite interactions among broadly distributed populations of the eastern oyster Crassostrea virginica and the protozoan Perkinsus marinus. Mar. Ecol. Prog. Ser., 139, 127-141.

Bushek D., S. E. Ford and I. Burt. 2012. Long-term patterns of an estuarine pathogen along a salinity gradient. J. Mar. Res., 70, 225-251.

Bushek, D., B. Landau and E. Scarpa. 2008. Perkinsus chesapeaki in stout razor clams Tagelus plebeius from Delaware Bay. Dis. Aquat. Org., 78, 243-247.

Cane, M. A. 2005. The evolution of El Niño, past and future. Earth Planet. Sci. Lett., 230, 227-240.

Carnegie, R. B. and E. M. Burreson. 2011. Declining impact of an introduced pathogen: Haplosporidium nelsoni in the oyster Crassostrea virginica in Chesapeake Bay. Mar. Ecol. Prog. Ser., 432, 1-15.

Choi, K-S., D. H. Lewis, E. N. Powell, P. F. Frelier and S. M. Ray. 1991. A polyclonal antibody developed from Perkinsus marinus hypnospores fails to cross react with other life stages of $P$. marinus in oyster (Crassostrea virginica) tissues. J. Shellfish Res., 10, 411-415.

Choi, K-S., D. H. Lewis, E. N. Powell and S. M. Ray. 1993. Quantitative measurement of reproductive output in the American oyster, Crassostrea virginica (Gmelin), using an enzyme-linked immunosorbent assay (ELISA). Aquacult. Fish. Manage., 24, 299-322.

Choi, K-S., E. N. Powell, D. H. Lewis and S. M. Ray. 1994. Instantaneous reproductive effort in female American oysters, Crassostrea virginica, measured by a new immunoprecipitation assay. Biol. Bull. (Woods Hole), 186, 41-61.

Choi, K-S., E. A. Wilson, D. H. Lewis, E. N. Powell and S. M. Ray. 1989. The energetic cost of Perkinsus marinus parasitism in oysters: quantification of the thioglycollate method. J. Shellfish Res., 8, 125-131.

Cook, T., M. Folli, J. Klinck, S. Ford and J. Miller. 1998. The relationship between increasing seasurface temperature and the northward spread of Perkinsus marinus (Dermo) disease epizootics in oysters. Estuar. Coast. Shelf Sci., 46, 587-597.

Cotter, S. C., L. E. B. Kruuk and K. Wilson. 2004. Costs of resistance: genetic correlations and potential trade-offs in an insect immune system. J. Evol. Biol., 17, 421-429.

Craig, A., E. N. Powell, R. R. Fay and J. M. Brooks. 1989. Distribution of Perkinsus marinus in Gulf coast oyster populations. Estuaries, 12, 82-91.

Crosby, M. P. and C. F. Roberts. 1990. Seasonal infection intensity cycle of the parasite Perkinsus marinus (and an absence of Haplosporidium spp.) in oysters from a South Carolina salt marsh. Dis. Aquat. Org., 9, 149-155.

Dawe, E. G., E. B. Colbourne and K. F. Drinkwater. 2000. Environmental effects on recruitment of short-finned squid (Illex illecebrosus). ICES J. Mar. Sci., 57, 1002-1013.

Dawson, C. E. 1955. Observations on the incidence of Dermocystidium marinum infection in oysters of Apalachicola Bay, Florida. Tex. J. Sci., 7, 47-56.

Detilleux, J. C. 2005. Genetic management of infectious diseases: a heterogeneous epidemio-genetic model illustrated with $S$. aureus mastitis. Genet. Sci. Evol., 37, 437-453.

Dittman, D. E., S. E. Ford and D. K. Padilla. 2001. Effects of Perkinsus marinus on reproduction and condition of the eastern oyster, Crassostrea virginica, depend on timing. J. Shellfish Res., 20, 1025-1034.

Dong, Q. 2005. Comparative studies of sperm cryopreservation of diploid and tetraploid Pacific oysters. Ph.D. Dissertation, Louisiana State University, Baton Rouge, Louisiana, 271 pp. 
Douglas, A. V. and P. J. Englehart. 1981. On a statistical relationship between Autumn rainfall in the central equitorial Pacific and subsequent winter precipitation in Florida. Mon. Weather Rev., 109, 2377-2382.

Duffy, M. A. and S. E. Forde. 2009. Ecological feedbacks and the evolution of resistance. J. Anim. Ecol., 78, 1106-1112.

Duffy, M. A., S. R. Hall, C. E. Cáceres and A. R. Ives. 2009. Rapid evolution, seasonality, and the termination of parasite epidemics. Ecology, 90, 1441-1448.

Duffy, M. A. and L. Sivars-Becker. 2007. Rapid evolution and ecological host-parasite dynamics. Ecol. Lett., 10, 44-53.

Dungan, C. F. and B. S. Roberson. 1993. Binding specificities of mono- and polyclonal antibodies to the protozoan oyster pathogen Perkinsus marinus. Dis. Aquat. Org., 15, 9-22.

Earnhart, C. G., M. A. Vogelbein, G. D. Brown, K. S. Reece and S. L. Kaattari. 2004. Supplementation of Perkinsus marinus cultures with host plasma or tissue homogenate enhances their infectivity. Appl. Environ. Microbiol., 70, 421-431.

Ebbesmeyer, C. C. and R. M. Strickland. 1995. Oyster condition and climate: evidence from Willapa Bay. Washington Sea Grant Program, Seattle, WN, USG-M9 95-02, 11 pp.

Elderd, B. D., J. Dushoff and G. Dwyer. 2008. Host-pathogen interactions, insect outbreaks, and natural selection for disease resistance. Am. Nat., 172, 829-842.

Encomio, V. G., S. M. Stickler, S. K. Allen Jr. and F-L. Chu. 2005. Performance of "natural Dermoresistant" oyster stocks - survival, disease, growth, condition and energy reserves. J. Shellfish Res., 24, 143-155.

Fabens, A. J. 1965. Properties and fitting of the von Bertalanffy growth curve. Growth, 29, 265-289.

Farley, C. A. 1975. Epizootic and enzootic aspects of Minchinia nelsoni (Haplosporida) disease in Maryland oysters. J. Protozool., 22, 418-427.

Fegley, S. R., S. E. Ford, J. N. Kraeuter and H. H. Haskin. 2003. The persistence of New Jersey's oyster seedbeds in the presence of oyster disease and harvest: the role of management. J. Shellfish Res., 22, 451-464.

Felsenstein, J. 1971. Inbreeding and variance effective numbers in populations with overlapping generations. Genetics, 68, 581-597.

Ford, S. E. 1988. Host-parasite interactions in eastern oysters selected for resistance to Haplosporidium nelsoni (MSX) disease: survival mechanisms against a natural pathogen. Am. Fish. Soc. Spec. Publ., 18, 206-224.

- 1996. Range extension by the oyster parasite Perkinsus marinus into the northeastern United States: response to climate change. J. Shellfish Res., 15, 45-56.

Ford, S. E. and H. H. Haskin. 1982. History and epizootiology of Haplosporidium nelsoni (MSX), an oyster pathogen in Delaware Bay, 1957-1980. J. Invertebr. Pathol., 40, 118-141.

Ford, S. E., A. Schotthoefer and C. Spruck. 1999. In vivo dynamics of the microparasite Perkinsus marinus during progression and regression of infections in eastern oysters. J. Parasitol., 85, 273285.

Ford, S. E. and R. Smolowitz. 2007. Infection dynamics of an oyster parasite in its newly expanded range. Mar. Biol. (Berl.), 151, 119-133.

Ford, S. E. and M. R. Tripp. 1996. Diseases and defense mechanisms, in The eastern oyster: Crassostrea virginica, V. S. Kennedy, R. I. E. Newell and A. F. Eble, eds., College Park, Maryland, Maryland Sea Grant College Program, 581-659.

Froese, R. 2006. Cube law, condition factor and weight-length relationships: history, meta-analysis and recommendations. J. Appl. Ichthyol., 22, 241-253.

Fromentin, J-M. and B. Planque. 1996. Calanus and environment in the eastern North Atlantic. II. Influence of the North Atlantic Oscillation in C. finmarchicus and C. helgolandicus. Mar. Ecol. Prog. Ser., 134, 111-118. 
Gaffney, P. M. and D. Bushek. 1996. Genetic aspects of disease resistance in oysters. J. Shellfish Res., $15,135-140$.

Gallagher, S. M. and R. Mann. 1986. Growth and survival of larvae of Mercenaria mercenaria (L) and Crassostrea virginica (Gmelin) relative to broodstock conditioning and lipid content of eggs. Aquaculture, 56, 105-121.

Goedken, M., B. Morsey, I. Sunila and S. de Guise. 2005. Immunomodulation of Crassostrea gigas and Crassostrea virginica cellular defense mechanisms by Perkinsus marinus. J. Shellfish Res., 24, 487-496.

Gómez-León, J., L. Villamil, S. A. Salger, R. H. Sallum, A. Remacha-Triviño, D. F. Leavitt and M. Gómez-Chiarri. 2008. Survival of eastern oysters Crassostrea virginica from three lines following experimental challenge with bacterial pathogens. Dis. Aquat. Org., 79, 95-105.

Gompertz, B. 1825. XXIV. On the nature of the function expressive of the law of human mortality, and on a new mode of determining the value of life contingencies. Phil. Trans. R. Soc. Lond., 115, $513-585$.

Guo, X., D. Hedgecock, W. K. Hershberger, K. Cooper and S. K. Allen Jr. 1998. Genetic determinants of protandric sex in the Pacific oyster, Crassostrea gigas Thunberg. Evolution, 52, 394-402.

Gray, J. S. and H. Christie. 1983. Predicting long-term changes in marine benthic communities. Mar. Ecol. Progr. Ser., 13, 87-94.

Hancock, D. A. 1973. The relationship between stock and recruitment in exploited invertebrates. Rapp. P-v. Réun Cons. Int. Explor. Mer, 164, 113-131.

Harding, J. M., R. Mann and M. J. Southworth. 2008. Shell length-at-age relationships in James River, Virginia, oysters (Crassostrea virginica) collected four centuries apart. J. Shellfish Res., 27, 1109-1115.

Harding, J. M., R. Mann, M. J. Southworth and J. A. Wesson. 2010. Management of the Piankatank River, Virginia, in support of oyster (Crassostrea virginica, Gmelin 1791) fishery repletion. J. Shellfish Res., 29, 867-888.

Harvell, C. D., C. E. Mitchell, J. R. Ward, S. A. Altizer, A. P. Dobson, R. S. Ostfeld and M. D. Samuel. 2002. Climate warming and disease risks for terrestrial and marine biota. Science (Wash. D.C.), 296, 2158-2162.

Haskin, H. H. and S. E. Ford. 1979. Development of resistance to Minchinia nelsoni (MSX) mortality in laboratory-reared and native oyster stocks in Delaware Bay. Mar. Fish. Rev., 41, 54-63.

Hasu, T., D. P. Benesh and E. T. Valtonen. 2009. Differences in parasite susceptibility and costs of resistance between naturally exposed and unexposed host populations. J. Evol. Biol., 22, 699-707.

Hayes, M. L., J. Bonaventura, T. P. Mitchell, J. M. Prospero, E. A. Shinn, F. van Dolah and R. T. Barber. 2001. How are climate and marine biological outbreaks functionally linked? Hydrobiologia, 460, 213-220.

Hayes, P. F. and R. W. Menzel. 1981. The reproductive cycle of early setting Crassostrea virginica (Gmelin) in the northern Gulf of Mexico, and its implications for population recruitment. Biol. Bull. (Woods Hole), 160, 80-88.

He, Y., S. Ford, D. Bushek, E. Powell, Z. Bao and X. Guo. 2012. Effective population sizes of eastern oyster Crassostrea virginica (Gmelin) populations in Delaware Bay, USA. J. Mar. Res., 70, 357-379.

Hedgecock, D. 1994. Does variability in reproductive success limit effective population sizes of marine organisms?, in Genetics and Evolution of Aquatic Organisms, A. R. Beaumont, ed., Chapman \& Hall, London, 122-134.

Hedgecock, D., V. Chow and R. S. Waples. 1992. Effective population numbers of shellfish broodstocks estimated from the temporal variance in allelic frequencies. Aquaculture, 108, 215-232. 
Hedgecock, D., S. Launey, A. I. Pudovkin, Y. Naciri, S. Lapègue and F. Bonhomme. 2007. Small effective number of parents $\left(N_{b}\right)$ inferred for a naturally spawned cohort of juvenile European flat oysters Ostrea edulis. Mar. Biol. (Berl.), 150, 1173-1182.

Hedgecock, D., D. J. McGoldrick and B. L. Bayne. 1995. Hybrid vigor in Pacific oysters: an experimental approach using crosses among inbred lines. Aquaculture, 137, 285-298.

Hedgecock, D., D. J. McGoldrick, D. T. Manahan, J. Vavra, N. Appelmans and B. L. Bayne. 1996. Quantitative and molecular genetic analyses of heterosis in bivalve molluscs. J. Exp. Mar. Biol. Ecol., 203, 49-59.

Héral, M. and J. M. Deslous-Paoli. 1983. Valeur énergétique de la chain de l'hur̂tre Crassostrea gigas estimée par mesures microcalorimetriques et par dosages biochimiques. Ocean. Acta, 6, 193-199.

Hewatt, W. G. and J. D. Andrews. 1954. Oyster mortality studies in Virginia. I Mortalities of oysters in trays at Gloucester Point, York River. Tex. J. Sci., 6, 121-133.

Hoenig, J. M. 1983. Empirical use of longevity data to estimate mortality rates. Fish. Bull., 83, 898-903.

Hofmann, E., D. Bushek, S. Ford, X. Guo, D. Haidvogel, D. Hedgecock, J. Klinck, C. Milbury, D. Narvaez, E. Powell, Y. Wang, Z. Wang, J. Wilkin, and L. Zhang. 2009. Understanding how disease and environment combine to structure resistance in estuarine bivalve populations. Oceanography, 22, 212-231.

Hofmann, E. E., J. M. Klinck, J. N. Kraeuter, E. N. Powell, R. E. Grizzle, S. C. Buckner and V. M. Bricelj. 2006. A population dynamics model of the hard clam, Mercenaria mercenaria: development of the age- and length-frequency structure of the population. J. Shellfish Res., 25, 417-444.

Hofmann, E. E., J. M. Klinck, E. N. Powell, S. Boyles and M. Ellis. 1994. Modeling oyster populations II. Adult size and reproductive effort. J. Shellfish Res., 13, 165-182.

Hofmann, E. E., E. N. Powell, J. M. Klinck and G. Saunders. 1995. Modeling diseased oyster populations I. Modelling Perkinsus marinus infections in oysters. J. Shellfish Res., 14, 121-151.

Hofmann, E. E., E. N. Powell, J. M. Klinck and E. A. Wilson. 1992. Modeling oyster populations. III. Critical feeding periods, growth and reproduction. J. Shellfish Res., 11, 399-416.

Hopkins, S. H. 1954. Oyster setting on the Gulf coast. Proc. Natl. Shellfish. Assoc., 45, 52-55.

Hurrell, J. W. and H. van Loon. 1997. Decadal variations in climate associated with the North Atlantic Oscillation. Climate Change, 36, 301-326.

Jaenike, J. 2002. Time-delayed effects of climate variation on host-parasite dynamics. Ecology, 83, 917-924.

Jensen, A. L. 1997. Origin of the relation between $\mathrm{K}$ and $\mathrm{L}_{\text {inf }}$ and synthesis of relations among life history parameters. Can. J. Fish. Aquat. Sci., 54, 987-989.

Kahya, E. and J. A. Dracup. 1993. U.S. streamflow patterns in relation to the El Niño/Southern Oscillation. Wat. Resour. Res., 29, 2491-2503.

Kang, S-G., K-S. Choi, A. A. Bulgakov, Y. Kim and S-Y. Kim. 2003. Enzyme-linked immunosorbent assay (ELISA) used in quantification of reproductive output in the Pacific oyster, Crassostrea gigas, in Korea. J. Exp. Mar. Biol. Ecol., 282, 1-21.

Kennedy, V. S. 1983. Sex ratios in oysters, emphasizing Crassostrea virginica from Chesapeake Bay, Maryland. Veliger, 25, 329-338.

Kennedy, V. S. and C. B. Krantz. 1982. Comparative gametogenic and spawning patterns of the oyster Crassostrea virginica (Gmelin) in central Chesapeake Bay. J. Shellfish Res., 2, 133-140.

Kim, Y. and E. N. Powell. 1998. Influence of climate change on interannual variation in population attributes of Gulf of Mexico oysters. J. Shellfish Res., 17, 265-274.

2006. Relationships among parasites and pathologies in sentinel bivalves: NOAA Status and Trends "Mussel Watch" Program. Bull. Mar. Sci., 79, 83-112.

2007. Distribution of parasites and pathologies in sentinel bivalves: NOAA status and trends "Mussel Watch" program. J. Shellfish Res., 26, 1115-1151. 
2009. Effects of climate variability on interannual variation in parasites, pathologies, and physiological attributes of bivalves from the U.S. East, Gulf, and West coasts. Environ. Bioindicators, 4, 67-96.

Kim, Y., E. N. Powell, T. L. Wade, B. J. Presley and J. M. Brooks. 1999. Influence of climate change on interannual variation in contaminant body burden in Gulf of Mexico oysters. Mar. Environ. Res., 48, 459-488.

- 2001. The geographic distribution of population health and contaminant body burden in Gulf of Mexico oysters. Arch. Environ. Contam. Toxicol., 41, 30-46.

Kobayashi, M., E. E. Hofmann, E. N. Powell, J. M. Klinck and K. Kusaka. 1997. A population dynamics model for the Japanese oyster, Crassostrea gigas. Aquaculture, 149, 285-321.

Kraeuter, J. N., S. Buckner and E. N. Powell. 2005. A note on a spawner-recruit relationship for a heavily exploited bivalve: the case of northern quahog (hard clams), Mercenaria mercenaria in Great South Bay, New York. J. Shellfish Res., 24, 1043-1052.

Kraeuter, J. N., S. Ford and M. Cummings. 2007. Oyster growth analysis: a comparison of methods. J. Shellfish Res., 26, 479-491.

Kraeuter, J. N., J. M. Klinck, E. N. Powell, E. E. Hofmann, S. C. Buckner, R. E. Grizzle and V. M. Bricelj. 2008. Effects of the fishery on the northern quahog (=hard clam, Mercenaria mercenaria L.) population in Great South Bay, New York: a modeling study. J. Shellfish Res., 27, 653-666.

Launey, S. and D. Hedgecock. 2001. High genetic load in the Pacific oyster Crassostrea gigas. Genetics, 159, 255-265.

Leethochavalit, S., K. Chalermwat, E. S. Upatham, K-S. Choi, P. Sawangwong and M. Kruatrachue. 2004. Occurrence of Perkinsus sp. in undulated surf clams Paphia undulata from the Gulf of Thailand. Dis. Aquat. Org., 60, 165-171.

Mackin, J. G. 1953. Incidence of infection of oysters by Dermocystidium in the Barataria Bay area of Louisiana. Natl. Shellfish. Assoc. Conv. Add., 22-35.

1959. A method of estimation of mortality rates in oysters. Proc. Natl. Shellfish. Assoc., 50, 41-51.

— 1962. Oyster disease caused by Dermocystidium marinus and other microorganisms in Louisiana. Publ. Inst. Mar. Sci. Univ. Texas, 7, 132-229.

Mackin, J. G. and S. H. Hopkins. 1962. Studies on oyster mortality in relation to natural environments and to oil fields in Louisiana. Publ. Inst. Mar. Sci. Univ. Tex., 7, 1-131.

Mackin, J. G. and A. K. Sparks. 1962. A study of the effect on oysters of crude oil loss from a wild well. Publ. Inst. Mar. Sci. Univ. Tex., 7, 230-261.

Mackin, J. G., B. Welch and C. Kent. 1950. A study of mortality of oysters of the Buras area of Louisiana. Texas A\&M Research Foundation Project Report, Project \#9; College Station, Texas, $41 \mathrm{pp}$.

Mancera, E. and J. Mendo. 1996. Population dynamics of the oyster Crassostrea rhizophorae from the Ciénaga Grande de Santa Marta, Colombia. Fish. Res., 26, 139-148.

Mann, R. and D. A. Evans, 2004. Site selection for oyster habitat rehabilitation in the Virginia portion of the Chesapeake Bay: a commentary. J. Shellfish Res., 23, 41-49.

Mann, R., M. Southworth, J. M. Harding and J. A. Wesson. 2009. Population studies of the native eastern oyster, Crassostrea virginica, (Gmelin, 1791) in the James River, Virginia, USA. J. Shellfish Res., 28, 193-220.

McCollough, C. B., B. W. Albright, G. R. Abbe, L. S. Barker and C. F. Dungan. 2007. Acquisition and progression of Perkinsus marinus infections by specific-pathogen-free juvenile oysters (Crassostrea virginica Gmelin) in a mesohaline Chesapeake Bay tributary. J. Shellfish Res., 26, 465-477. 
McLaughlin, S. M., E. E. Elsayed and M. Faisal. 2000. Analysis of extracellular proteins of two Perkinsus spp. isolated from the softshell clam Mya arenaria in vitro. Comp. Biochem. Physiol. B Comp. Biochem., 126, 587-598.

Montes, J. F., M. Durfort and J. Garcia-Valero. 2005. Ultrastructural localization of antigenic determinants conserved during Perkinsus atlanticus trophozoite to prezoosporangium differentiation. Dis. Aquat. Org., 66, 33-40.

Moore, H. F. 1907. Survey of oyster bottoms in Matagorda Bay, Texas. U.S. Bur. Fish Doc., 610, 86 pp.

Morton, B. 1990. Life cycle and sexual strategy of Saccostrea cucullata (Bivalvia: Ostreidae) from a Hong Kong mangrove. Am. Malacol. Bull., 8, 1-8.

Mouritsen, K. N. and R. Poulin. 2002. Parasitism, climate oscillations and the structure of natural communities. Oikos, 97, 462-468.

Mullin, M. M. 1995. The Californian El Niño of 1992 and the fall of Calanus. CCOFI Rep., 36, 175-178.

Ngo, T. T. T. and K-S. Choi. 2004. Seasonal changes of Perkinsus and Cercaria infections in the Manila clam Ruditapes philippinarum from Jeju, Korea. Aquaculture, 239, 57-68.

Ngo, T. T. T., S-G. Kang, D-H. Kang, P. Sorgeloos and K-S. Choi. 2006. Effect of culture depth on the proximate composition and reproduction of the Pacific oyster, Crassostrea gigas from Gosung Bay, Korea. Aquaculture, 253, 712-720.

Notaro, M., W-C. Wang and W. Gong. 2006. Model and observational analysis of the northeast U.S. regional climate and its relationship to the PNA and NAO patterns during early winter. Mon. Weather Rev., 134, 3479-3505.

Oliva M. E., I. Barrios, S. Thatje and J. Laudie. 2008. Changes in prevalence and intensity of infection of Profilicollis altmani (Perry, 1942) cystacanth (Acanthocephala) parasitizing the mole crab Emerica analoga (Stimpson, 1857): an El Niño cascade effect? Helgol. Mar. Res., 62 (Suppl. 1), S57-S62.

Oliver, L. M., W. S. Fisher, A. K. Volety and Z. Malaeb. 2003. Greater hemocyte bactericidal activity in oysters (Crassostrea virginica) from a relatively contaminated site in Pensacola Bay, Florida. Aquat. Toxicol., 64, 363-373.

Owen, H. M. 1953. The relationship of high temperatures and low rainfall to oyster production in Louisiana. Bull. Mar. Sci. Gulf Caribb., 3, 34-43.

Panko, C., V. Encomio, J. Barreto and A. K. Volety. 2008. In vitro and in vivo evaluation of quinine as a potential anti-protozoal for the eastern oyster parasite Perkinsus marinus. J. Shellfish Res., 27, 789-793.

Parry, G. D. 1981. The meanings of r- and k-selection. Oecologia (Berl.), 48, 260-264.

Paynter, K. T. 1996. The effects of Perkinsus marinus infection on physiological processes in the eastern oyster, Crassostrea virginica. J. Shellfish Res., 15, 119-125.

Peterson, C. H. and H. C. Summerson. 1992. Basin-scale coherences of population dynamics of an exploited marine invertebrate, the bay scallop: implications of recruitment limitation. Mar. Ecol. Prog. Ser., 90, 257-272.

Powell, E. N., K. A. Ashton-Alcox, J. N. Kraeuter, S. E. Ford and D. Bushek. 2008. Long-term trends in oyster population dynamics in Delaware Bay: regime shifts and response to disease. J. Shellfish Res., 27, 729-755.

Powell, E. N. and H. C. Cummins. 1985. Are molluscan maximum life spans determined by long-term cycles in benthic communities? Oecologia (Berl.), 67, 177-182.

Powell, E. N., J. D. Gauthier, E. A. Wilson, A. Nelson, R. R. Fay and J. M. Brooks. 1992. Oyster disease and climate change. Are yearly changes in Perkinsus marinus parasitism in oysters (Crassostrea virginica) controlled by climatic cycles in the Gulf of Mexico? P.S.Z.N.I.: Mar. Ecol., 13, 243-270. 
Powell, E. N., J. M. Klinck, K. A. Ashton-Alcox and J. N. Kraeuter. 2009a. Multiple stable reference points in oyster populations: biological relationships for the eastern oyster (Crassostrea virginica) in Delaware Bay. Fish. Bull., 107, 109-132.

2009b. Multiple stable reference points in oyster populations: implications for reference pointbased management. Fish. Bull., 107, 133-147.

Powell, E. N., J. M. Klinck, X. Guo, E. E. Hofmann, S. E Ford and D. Bushek. 2011a. The potential for oysters, Crassostrea virginica, to develop resistance to Dermo disease in the field: evaluation using a gene-based population dynamics model. J. Shellfish Res., 30, 685-712.

Powell, E. N., J. M. Klinck and E. E. Hofmann. 1996. Modeling diseased oyster populations. II. Triggering mechanisms for Perkinsus marinus epizootics. J. Shellfish Res., 15, 141-165.

- 2011b. Generation time and the stability of sex-determining alleles in oyster populations as deduced using a gene-based population dynamics model. J. Theor. Biol., 271, 27-43.

Powell, E. N., J. M. Morson, K. A. Ashton-Alcox and Y. Kim. 2012. Accommodation of the sex ratio in eastern oysters Crassostrea virginica to variation in growth and mortality across the estuarine salinity gradient in Delaware Bay. J. Mar. Biol. Assoc. U. K.

Powell, E. N., J. Morson and J. M. Klinck. 2011c. Application of a gene-based population dynamics model to the optimal egg size problem: why do bivalve planktotrophic eggs vary in size? J. Shellfish Res. 30, 403-423.

Powell, E. N. and R. J. Stanton Jr. 1985. Estimating biomass and energy flow of molluscs in paleocommunities. Palaeontology (Lond.), 28, 1-34.

Press, W. H., B. P. Flannery, S. A. Teukolsky and W. T. Vettering. 1986. Numerical recipes, the art of scientific computing. Cambridge University Press, Cambridge.

Quick Jr., J. A. and J. G. Mackin. 1971. Oyster parasitism by Labyrinthomyxa marina in Florida. Fl. Dept. Nat. Resour. Prof. Pap. Ser., No. 13, 55 pp.

Ragone Calvo, L. M., G. W. Calvo and E. M. Burreson. 2003. Dual disease resistance in a selectively bred eastern oyster, Crassostrea virginica, strain tested in Chesapeake Bay. Aquaculture 220, 6987.

Ragone Calvo, L. M., R. L. Wetzel and E. M. Burreson. 2001. Development and verification of a model for the population dynamics of the protistan parasite, Perkinsus marinus, within its host, the eastern oyster, Crassostrea virginica, in Chesapeake Bay. J. Shellfish Res., 20, 231-241.

Ray, S. M. 1996. Historical perspective on Perkinsus marinus disease of oysters in the Gulf of Mexico. J. Shellfish Res., 15, 9-11.

Ray, S. M. and A. C. Chandler. 1955. Dermocystidium marinum, a parasite of oysters. Exp. Parasitol., 4, 172-200.

Reece, K. S., D. Bushek, K. L. Hudson and J. E. Graves. 2001. Geographic distribution of Perkinsus marinus genetic strains along the Atlantic and Gulf coasts of the USA. Mar. Biol. (Berl.), 139, 1047-1055.

Rothschild, B. J., J. S. Ault, P. Goulletquer and M. Héral. 1994. Decline of the Chesapeake Bay oyster populations: a century of habitat destruction and overfishing. Mar. Ecol. Prog. Ser., 111, 29-39.

Saunders, G. L., E. N. Powell and D. H. Lewis. 1993. A determination of in vivo growth rates for Perkinsus marinus, a parasite of the Eastern oyster Crassostrea virginica (Gmelin, 1791). J. Shellfish Res., 12, 229-240.

Schmidt, N. and M. E. Luther. 2002. ENSO impacts on salinity in Tampa Bay, Florida. Estuaries, 25, 976-984.

Schneider, D. S. and J. S. Ayres. 2008. Two ways to survive infection: what resistance and tolerance can teach us about treating infectious diseases. Nat. Rev. Immunol., 8, 889-895. 
Schoener, A. and D. F. Tufts. 1987. Changes in oyster condition index with El Niño-Southern Oscillation events at $46^{\circ} \mathrm{N}$ in an eastern Pacific bay. J. Geophys. Res., 92, 14429-14435.

Sokolova, I. M., J. D. Oliver and L. J. Leamy. 2006. An AFLP approach to identify genetic markers associated with resistance in Vibrio vulnificus and Perkinsus marinus in eastern oysters. J. Shellfish Res., 25, 95-100.

Soniat, T. M. 1985. Changes in levels of infection of oysters by Perkinsus marinus, with special reference to the interaction of temperature and salinity upon parasitism. N.E. Gulf Sci., 7, 171174.

Soniat, T. M. and M. S. Brody. 1988. Field validation of a habitat suitability index model for the American oyster. Estuaries, 11, 87-95.

Soniat, T. M. and J. D. Gauthier. 1989. The prevalence and intensity of Perkinsus marinus from the mid northern Gulf of Mexico, with comments on the relationship of the oyster parasite to temperature and salinity. Tul. Stud. Zool. Bot., 27, 21-27.

Soniat, T. M., E. E. Hofmann, J. M. Klinck and E. N. Powell. 2009. Differential modulation of eastern oyster (Crassostrea virginica) disease parasites by the El Niño-Southern Oscillation and the North Atlantic Oscillation. Int. J. Earth Sci., 98, 99-114.

Soniat, T. M., J. M. Klinck, E. N. Powell and E. E. Hofmann. 2006. Understanding the success and failure of oyster populations: climatic cycles and Perkinsus marinus. J. Shellfish Res., 25, 83-93.

Stauber, L. A. 1950. The problem of physiological species with special reference to oysters and oyster drills. Ecology, 31, 109-118.

Stearns, S. 1976. Life-history tactics: a review of the ideas. Quart. Rev. Biol., 51, 3-47.

Thatje, S., O. Heilmayer and J. Laudien. 2008. Climate variability and El Niño Southern Oscillation: implications for natural coastal resources and management. Helgol. Mar. Res., 62 (Suppl. 1), S5S14.

Tolan, J. M. 2007. El Niño-Southern Oscillation impacts translated to the watershed scale: estuarine salinity patterns along the Texas Gulf coast, 1982 to 2004. Estuar. Coast. Shelf Sci., 72, 247-260.

Tunberg, B. G. and W. G. Nelson. 1998. Do climatic oscillations influence cyclical patterns of soft bottom macrobenthic communities in the Swedish west coast? Mar. Ecol. Prog. Ser., 170, 85-94.

Volety, A. K., F. O. Perkins, R. Mann and P. R. Hershberg. 2000. Progression of diseases caused by the oyster parasites, Perkinsus marinus and Haplosporidium nelsoni, in Crassostrea virginica on constructed intertidal reefs. J. Shellfish Res., 19, 341-347.

Waaij, E. H. van der, P. Bijma, S. C. Bishop and J. A. M. van Arendonk. 2000. Modeling selection for production traits under constant infection pressure. J. Anim. Sci., 78, 2809-2820.

Wang, Y. and X. Guo. 2007. Development and characterization of EST-SSR markers in the eastern oyster Crassostrea virginica. Mar. Biotechnol., 9, 500-511.

Wang, Y., Z. Xu, J. C. Pierce and X. Guo. 2005. Characterization of eastern oyster (Crassostrea virginica Gmelin) chromosomes by fluorescence in situ hybridization with bacteriophage $\mathrm{P} 1$ clones. Mar. Biotechnol., 7, 207-214.

Wang, Z. P., X. Guo, S. K. Allen Jr. and R. Wang. 1999. Aneuploid Pacific oyster (Crassostrea gigas Thunberg) as incidentals from triploid production. Aquaculture, 173, 347-357.

Wilson, E. A., E. N. Powell, M. A. Craig, T. L. Wade and J. M. Brooks. 1990. The distribution of Perkinsus marinus in Gulf coast oysters: its relationship with temperature, reproduction, and pollutant body burden. Int. Rev. Gesamten Hydrobiol., 75, 533-550.

Wilson, E. A., E. N. Powell, T. L. Wade, R. J. Taylor, B. J. Presley and J. M. Brooks. 1992. Spatial and temporal distributions of contaminant body burden and disease in Gulf of Mexico oyster populations: the role of local and large-scale climatic controls. Helgol. Meeresunters., 46, $201-$ 235. 
Wilson-Ormond, E. A., E. N. Powell and S. M. Ray. 1997. Short-term and small-scale variation in food availability to natural oyster populations: food, flow and flux. P.S.Z.N.I. Mar. Ecol., 18, 1-34. Yoo, S. K. and M. S. Yoo, 1973. Biological studies on oyster culture (II) morphological characteristics of the oyster, Crassostrea gigas. Bull. Korean Fish. Soc., 6, 65-74.

Zbinden, M., C. R. Haag and D. Ebert. 2008. Experimental evolution of field populations of Daphnia magna in response to parasite treatment. J. Evol. Biol., 21, 1068-1078.

Zuur, A. F. and G. J. Pierce. 2004. Common trends in northeast Atlantic squid time series. J. Sea Res., $52,57-72$.

Received: 10 October, 2011; revised: 19 April, 2012. 